
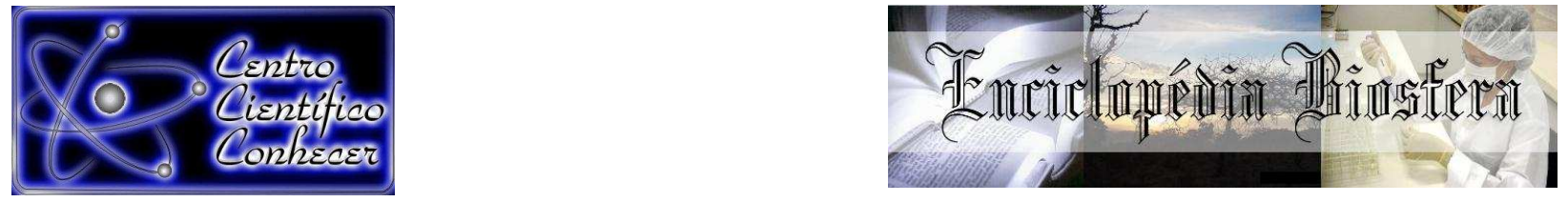

\title{
ANÁLISE DOS PARÂMETROS FÍSICO-QUÍMICOS DA ÁGUA EM FUNÇÃO DO COMPORTAMENTO DA MARÉ: UM ESTUDO DE CASO NO IGARAPÉ TUCUNDUBA, BELÉM - PA
}

Gundisalvo Piratoba Morales ${ }^{1}$, Laís Freitas Moreira dos Santos², Yuri Aguiar Ferreira $^{3}$, Octávio Cascaes Dourado Júnior ${ }^{4}$ Manuel Alejandro Piratoba Vera ${ }^{5}$

${ }^{1}$ Prof. Doutor do curso de Engenharia Ambiental da Universidade do Estado do Pará

²Engenheira Ambiental pela Universidade do Estado do Pará

${ }^{3}$ Estudante de Engenharia Ambiental da Universidade do Estado do Pará

${ }^{4}$ Professor Doutor do curso de Engenharia Ambiental da Universidade do Estado do

Pará

${ }^{3}$ Estudante de Engenharia Ambiental do IESAM

gundymorales@gmail.com

Recebido em: 08/09/2015 - Aprovado em: 14/11/2015 - Publicado em: 01/12/2015

DOI: http://dx.doi.org/10.18677/Enciclopedia_Biosfera_2015_076

\begin{abstract}
RESUMO
O crescimento populacional desenfreado causou um processo de ocupação desordenada das cidades. Em Belém, essa ocupação irregular ocorre principalmente nas áreas de várzea, as quais sofrem influência diária de marés. Esse tipo de ocupação representa uma grande problemática socioambiental, como é o caso do Igarapé Tucunduba, o qual apresenta uma ocupação irregular ao longo de suas margens, especialmente no trecho próximo à sua foz, onde deságua no Rio Guamá. A presença dessa ocupação nas margens do Igarapé resulta no despejo de grande quantidade de matéria orgânica in natura, degradando o corpo hídrico. Dessa forma, o trabalho objetivou acompanhar o comportamento de alguns parâmetros físicoquímicos durante uma enchente e uma vazante num período de tempo de 12 horas contínuas, num único ponto de coleta, localizado na foz do Igarapé em questão, onde as amostras foram coletadas paralelamente com mediadas de altura do nível de água na entrada e saída da maré. As amostras de água foram coletadas a cada 90 minutos enquanto que o registro de a altura da lâmina da água foi medida durante a entrada e saída da maré a cada 30 minutos. Foi identificado que na enchente, as amostras tinham maior influência da água do Rio Guamá, enquanto que na vazante, tinham maior influência da água do Igarapé Tucunduba. As amostras coletadas na vazante, então, apresentaram parâmetros alterados e maior degradação ambiental, por conta das atividades antrópicas desenvolvidas nas margens do Igarapé. Os parâmetros de Condutividade, Alcalinidade, STD, OD, DBO e Cloreto foram os mais representativos da degradação do Igarapé e da diferença clara de comportamento na enchente e na vazante.
\end{abstract}

PALAVRAS-CHAVE: Degradação ambiental, maré, Parâmetros físico-químicos, Várzea, Tucunduba. 


\title{
ANALYSIS OF WATER'S PHYSICAL-CHEMICAL PARAMETERS AND ITS RELATION WITH THE TIDAL BEHAVIOUR: A STUDY CASE AT THE TUCUNDUBA CREEK, BELÉM - PA
}

\begin{abstract}
The fast and unbridled population growth started a process of cities' disordered occupation. In Belém, this irregular occupation is concentrated in the floodplain areas, which suffer the daily influence of the tides. This type of occupation represents a huge social and environmental problem, as it happens in the case of the Tucunduba Creek, which has an irregular occupation along its banks, especially in the stretch close to its mouth, where it flows into the Guamá River. The presence of the bank's occupation results in the release of big quantities of organic matter into the water, degrading the creek. Thus, this paper aims to analyse the behaviour of some physicochemical parameters of water quality during a flow and an ebb, with the duration of 12 hours, in a single water sampling point, in the mouth of the Tucunduba Creek, using an adapted methodology of tidal control. The samples were taken every 90 minutes and the height of the water depth every 30 minutes .It was identified that during the flow, the water had more influence of the Guamá River, and during the ebb, of the Tucunduba Creek. So, the samples collected during the ebb presented altered results and high levels of degradation, due to the anthropic activities developed at the creek's banks. The parameters of conductivity, alkalinity, total dissolved solids, DO, BOD, and Clorets were the most representatives of the creek's degradation and of the behaviour's difference between the flow and the ebb.
\end{abstract}

KEYWORDS: Floodplain. Tucunduba. Environmental Degradation. Tides. Physicalchemical parameters.

\section{INTRODUÇÃO}

O crescimento populacional, associado à urbanização, ocasionou um crescimento acelerado e desordenado das cidades, com a consequente ocupação de espaços urbanos inadequados para moradia. NETO \& CARDOSO (2012) afirmam que a água é um dos principais recursos naturais, e que vem sofrendo grandes pressões da evolução das cidades e ocupação urbana, principalmente na Amazônia, onde se verifica forte influência das águas sobre a distribuição da população no território, pelo caráter logístico que os rios sempre tiveram na região. Em Belém, a ocupação desordenada ocorre frequentemente em áreas de várzea.

A topografia de Belém, de maneira geral, é plana e baixa, com uma superfície acidentada e poucas elevações. Nessa superfície, podem ser encontrados dois tipos de território, as planícies de várzea e a terra firme. As planícies de várzea possuem topografia entre 0 e $4 \mathrm{~m}$ acima do nível do mar e são naturalmente alagáveis (MATOS, 2010).

As várzeas estão presentes no entorno da baía do Guajará, do rio Guamá e dos baixos cursos dos igarapés que recortam a Região Metropolitana de Belém, sofrendo pequenas inundações diárias, que ocorrem pela influência das marés ou de índices pluviométricos intensos (PIMENTEL, 2012).

Ao longo das décadas de 60 e 80 o número de ocupações irregulares cresceu na cidade de Belém, em função do elevado índice de desemprego e empregos informais. Muitas famílias foram levadas a habitar áreas de periferia, o que levou ao surgimento de núcleos periféricos no processo de ocupação. Esse período foi marcado então por um adensamento populacional acelerado e por um processo de 
valorização cada vez maior dos espaços urbanos centrais (SANTOS, 2010).

A metrópole de Belém apresenta grandes contradições no que diz respeito à produção e dinâmica de seu espaço urbano, pois durante muito tempo, as políticas de planejamento urbano eram voltadas para atender aos interesses das elites e do setor imobiliário formal. Este fato contribuiu para a afirmação de um planejamento segregador e excludente nas políticas públicas de Belém (COLARES, 2013).

Assim, as áreas de várzea, também conhecidas como "baixadas", representam hoje a expressão da cidade informal em Belém, construída a partir da ocupação de terras desvalorizadas pelo mercado formal, consideradas inadequadas à ocupação, ainda que próximas da porção mais central e infraestruturada da cidade. Como afirma RODRIGUES et al., (2012), essa ocupação nas áreas de várzea degrada o corpo hídrico, além de provocar precariedade habitacional, com a falta de saneamento e infraestrutura.

Em Belém, a ocupação desordenada ocorre principalmente nas áreas de várzea, ao longo dos diversos igarapés e córregos que cortam a cidade, o que representa uma problemática socioambiental, na medida em que causa alta degradação da qualidade ambiental dos corpos hídricos em detrimento da qualidade de vida da população (RODRIGUES et al, 2012).

Nesse contexto, encontra-se o Igarapé Tucunduba, o qual apresenta uma ocupação irregular ao longo de suas margens, principalmente no trecho próximo ao ponto em que deságua no Rio Guamá, onde estão situadas as Comunidades do Riacho Doce e Pantanal.

A presença dessa ocupação nas margens do Igarapé resulta no despejo de resíduos sólidos e esgoto doméstico sem seu devido tratamento, traduzido na descarga de grande quantidade de matéria orgânica in natura impactando e degradando o Igarapé, o que demonstra a necessidade de análise da qualidade da água do Igarapé, com uma metodologia eficiente, capaz de levar em consideração as peculiaridades dos corpos hídricos típicos de Belém, os quais sofrem influência diária de maré.

Dessa forma, o presente trabalho objetiva analisar a qualidade de água do Igarapé Tucunduba, acompanhando o comportamento de alguns parâmetros físicoquímicos durante uma enchente e vazante, com a duração de 12 horas contínuas, num único ponto de coleta, localizado na foz do Igarapé em questão, utilizando uma metodologia modificada de MORALES (2002) e MATOS et al., (2011).

\section{MATERIAL E MÉTODOS}

\section{DESCRIÇÃO DA ÁREA DE ESTUDO}

A topografia de Belém, de maneira geral, é plana e baixa, com uma superfície acidentada e poucas elevações. Nessa superfície, podem ser encontrados dois tipos de território, as planícies de várzea e a terra firme. As planícies de várzea possuem topografia entre 0 e $4 \mathrm{~m}$ acima do nível do mar e são naturalmente alagáveis (SUDAM, 1979).

As várzeas estão presentes no entorno da baía do Guajará, do rio Guamá e dos baixos cursos dos igarapés que recortam a Região Metropolitana de Belém, sofrendo pequenas inundações diárias, que ocorrem pela influência das marés ou de índices pluviométricos intensos (FERREIRA, 1995). Para MORÁN (1990), a várzea de estuário diferencia-se dos outros tipos de várzea da Amazônia pela influência diária da água salina, das marés e pela riqueza aquática. 


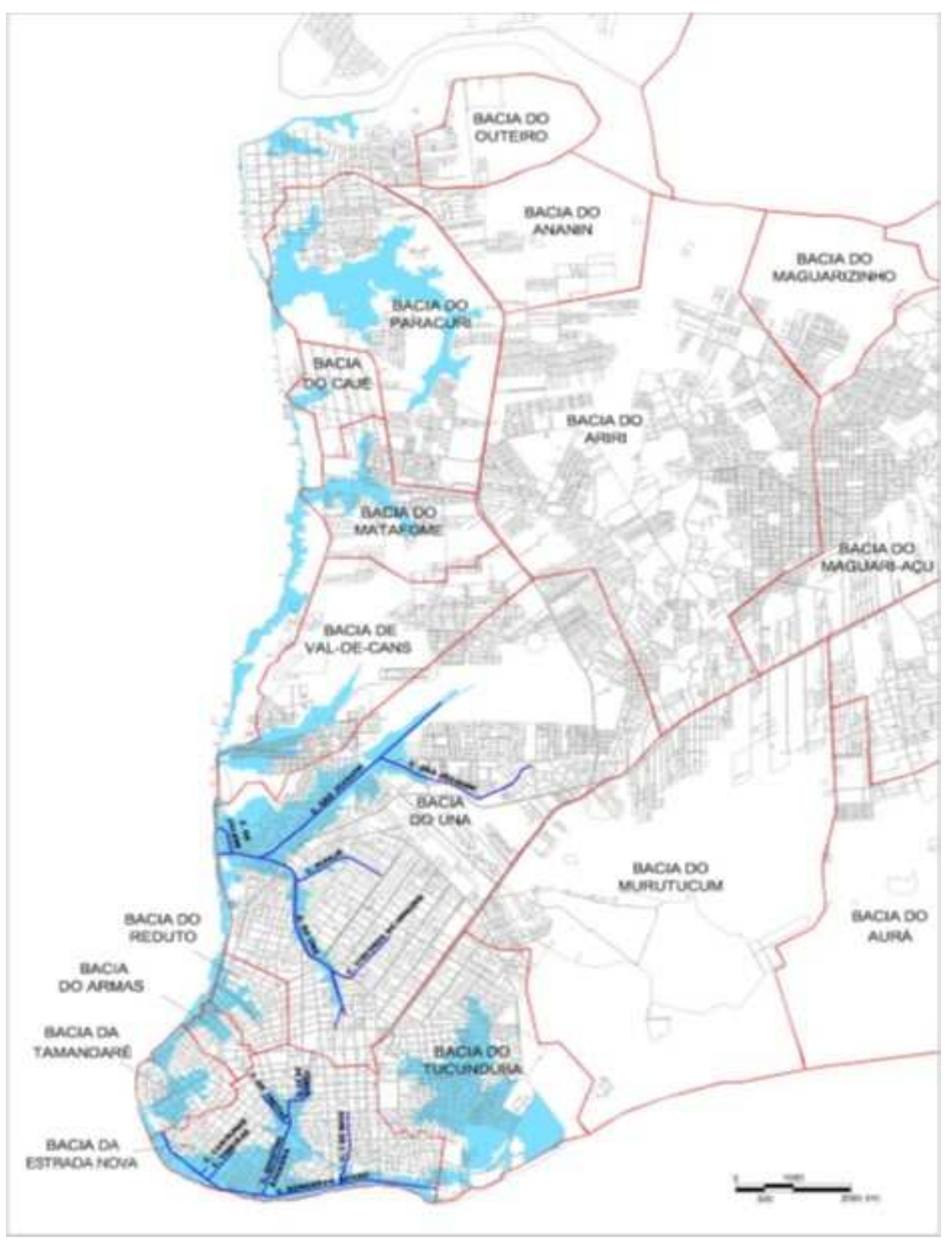

FIGURA 1 - Localização das Bacias de Drenagem de Belém Fonte: CODEM, 2000.

A área de estudo corresponde a um ecossistema de várzea estuarino, caracterizado como alto estuário, que sofre influências do Rio Guamá, que por sua vez, sofre influência de marés. A Bacia do Tucunduba é uma das 14 bacias hidrográficas de Belém, localizada a sudeste da cidade, pertence à bacia do Rio Guamá e possui uma área aproximada de 1.055 ha, das quais 575 ha correspondem a áreas de várzea, o que representa $21,02 \%$ das áreas de várzea de Belém (DNOS, 1974) (Figura 1).

O Igarapé Tucunduba é o principal corpo hídrico da bacia, com 3.600 metros de extensão, onde $37 \%$ de sua área de várzea apresenta cotas topográficas inferiores à $3,70 \mathrm{~m}$, valor de referência que corresponde ao valor da maior altura da maré registrada na área (MATOS, 2010). O Igarapé Tucunduba apresenta comportamento de corpo hídrico lótico segundo ESTEVES (2011), possuindo sua nascente na Tv. Angustura e sua foz na margem direita do Rio Guamá, dentro do Campus da Universidade Federal do Pará (Figura 2). 
O Igarapé Tucunduba faz parte do perímetro urbano de Belém, no entanto, suas margens não possuem a faixa de preservação de $30 \mathrm{~m}$, conforme estabelece $o$ Código Florestal (BRASIL, 2012), sofrendo ao longo de seu percurso intensos impactos ambientais, provenientes de atividades antrópicas realizadas pela população de baixa renda, que se apoderou da área através de ocupações desordenadas (SANTOS, 2010).

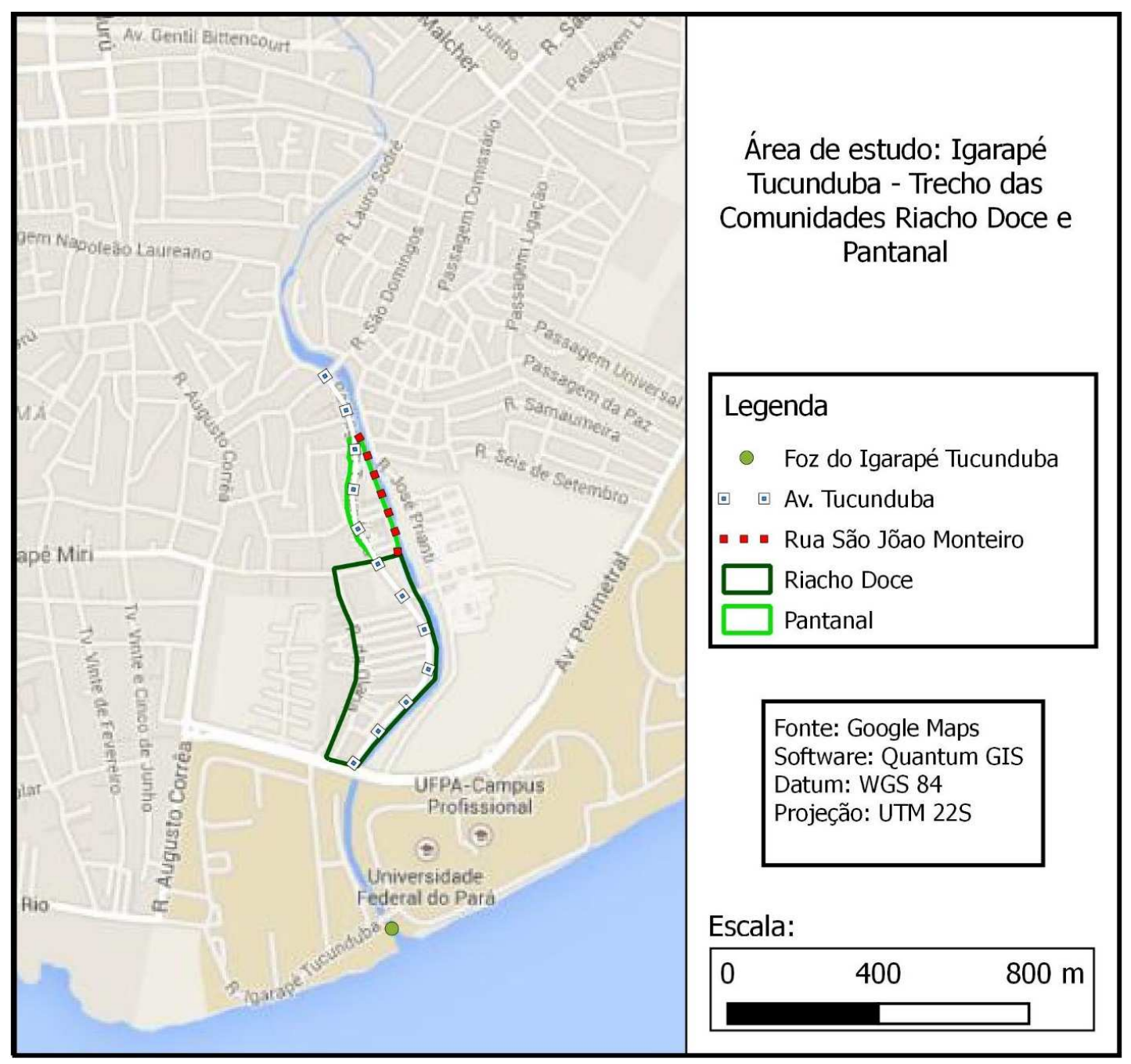

FIGURA 2 - Trecho do Igarapé Tucunduba onde estão situadas as Comunidades Riacho Doce e Pantanal

MATOS (2010) afirma que a várzea do Igarapé Tucunduba ficou à margem da expansão da malha urbana de Belém até o início da década de 60. No entanto, na década de 70, ocorreram grandes transformações no contexto político, econômico e social de Belém, onde a várzea do igarapé foi ocupada e utilizada para construção de moradias subnormais para abrigar grande fluxo de pessoas provenientes de zonas rurais e outros estados.

No processo de ocupação, as margens do Igarapé Tucunduba foram submetidas ao desmatamento e à construção das palafitas, transformando o igarapé no principal corpo receptor da poluição causada pela destinação inadequada de resíduos sólidos e esgoto sanitário sem tratamento (FERREIRA, 1995). 
Essa ocupação sem planejamento causou uma intensa degradação ambiental do Igarapé e péssimas condições de qualidade de vida da população, que carece de serviços básicos que deveriam ser providos pelo Poder Público. Nesse contexto de ocupação urbana de várzeas na cidade de Belém, especialmente no Igarapé Tucunduba, originaram-se as comunidades do Riacho Doce e Pantanal (Figura 2).

Baseada nessa ocupação no trecho do Igarapé próximo à sua foz - onde deságua no Rio Guamá, foi escolhido o ponto de controle de maré, onde foram coletadas amostras de água durante um período de 12 horas, para avaliar o impacto da degradação causada pela ocupação antrópica nas suas margens. A Figura 2 mostra onde estão situadas as comunidades e a foz do lgarapé, ponto em que foram realizadas as coletas.

As comunidades Riacho Doce e Pantanal ocupam a margem esquerda do Igarapé Tucunduba. A margem direita pertence à Universidade Federal do Pará e não deve ser ocupada, embora haja uma invasão ocupando a margem direita, com palafitas, no trecho da comunidade Pantanal.

\section{PROCEDIMENTOS}

Para a coleta das amostras e controle da altura da maré foi selecionado um único ponto de amostragem próximo à foz do Igarapé Tucunduba perto da sua desembocadura para o rio Guamá (coordenadas geográficas: 1²8'33.4"S e 4827'14.8”W), localizado no campus da Universidade Federal do Pará (Figura 2).

Foi utilizada uma metodologia modificada de MORALES (2002) e MATOS et al., (2011), para determinar o Comportamento de Parâmetros Físicos, Quimicos e Biológicos da Água em Função da Dinâmica da Maré Durante uma Enchente e uma Vazante Contínua, num intervalo de tempo de 12 horas seguidas. Essa metodologia é válida para ecossistemas estuarinos, em especial rios ou igarapés que sofrem influência diária de marés.

A coleta das amostras de água do igarapé Tucunduba no ponto selecionado, foi realizada a intervalos de tempo de 90 minutos, ao longo de 12 horas, totalizando um total de 9 amostras. A coleta foi iniciada no final da vazante ou BAIXA-MAR $\mathrm{BM}^{1}$, abrangendo toda a enchente, atingindo a PREAMAR $\mathrm{PM}^{2}$ e terminando a mesma novamente no final vazante. Visando obter informações preliminares do comportamento de alguns parâmetros físico-químicos em relação à influência antrópica da ocupação da bacia do igarapé Tucunduba e do comportamento da maré no local, foi selecionada a data na qual o final da primeira e segunda BM ocorreriam próximo das 6:00 e 18:00 horas, respectivamente. Embora os dados gerados numa única data não sejam suficientes para obter informações conclusivas, os mesmos serão usados como informações preliminares para outros estudos mais apurados considerando o ciclo hidrológico. Para isso, foram realizadas observações prévias na área para determinar a hora da BM e PM, em relação aos dados disponibilizados pelo site da Marinha do Brasil para o Porto de Belém.

$\mathrm{Na}$ figura 3, temos a informação disponibilizada no site da Marinha do Brasil para o Porto de Belém, a qual mostrava o dia 08 de Outubro de 2014 como o mais indicado para realizar a coleta e controle da maré, em virtude que a primeira e segunda BAIXAMAR aconteceriam às $06: 24$ e às 18:49, respectivamente. Foram utilizadas as informações do Porto de Belém por conta da proximidade com o ponto de coleta selecionado. 
PORTO DE BELÉM (ESTADO DO PARÁ)

Latitude: $01^{\circ} 26.2^{\prime} \mathrm{S}$

Instituição: IAGS
Longitude: $048^{\circ} 29.6^{\prime} \mathrm{W}$

100 Componentes
Fuso: +03.0

Nivel Médio: $1.81 \mathrm{~m}$
Ano: 2014

Carta: 00320

\begin{tabular}{cccc} 
Lua & Dia & Hora & Alt.(m) \\
& & & \\
\hline & WED $08 / 10 / 2014$ & $06: 24$ & 0.2 \\
& & $11: 06$ & 3.5 \\
& & $18: 49$ & 0.2 \\
& & $23: 13$ & 3.5
\end{tabular}

FIGURA 3 - Tabua das Marés do Porto de Belém no dia 08 de Outubro de Fonte: www.mar.mil.br/dhn/chm/box-previsao-mare/tabuas (2014).

As amostras de água foram coletadas seguindo as orientações da Standard Methods for the Examination of Water and Wastewater 21th Edition (APHA, 2005), utilizando recipientes e fixadores necessários de acordo com as mitologias dos parâmetros analisados e relacionados na Tabela 1.

Os parâmetros de $\mathrm{pH}$ e temperatura foram realizados em campo, no momento da coleta das amostras. As nove amostras coletadas foram acondicionadas, transportadas e analisadas no laboratório Universo Amazônia Ltda, seguindo a metodologia descrita na Tabela 1.

TABELA 1 - Métodos de análise dos parâmetros físico-químicos.

\begin{tabular}{|c|c|}
\hline Parâmetro & Método \\
\hline Temperatura & $\begin{array}{l}\text { Determinada in loco pelo através de termômetro de } \\
\text { mercúrio. }\end{array}$ \\
\hline Potencial Hidrogeniônico & $\begin{array}{l}\text { Determinado in loco pelo método eletrométrico (Standard } \\
\text { Methods for the Examination of Water \& Wastewater 20Th } \\
\text { - APHA-AWWA-WEF - method } 4500 \mathrm{H}+\text { - B), utilizando-se } \\
\text { de pHmetro marca Hanna, modelo } 8316 \text {. }\end{array}$ \\
\hline Cor & $\begin{array}{l}\text { Determinada pelo método da comparação visual (Standard } \\
\text { Methods for the Examination of Water \& Wastewater 20Th } \\
\text { - APHA - AWWA-WEF - method } 2120 \text { - B). }\end{array}$ \\
\hline Turbidez & $\begin{array}{l}\text { Determinado pelo método Nefelométrico (Standard } \\
\text { Methods for the Examination of Water \& Wastewater 20Th } \\
\text { - APHA - AWWA-WEF - method 2130 - B), utilizou-se o } \\
\text { turbidímetro da marca Quimis, modelo Q279P. }\end{array}$ \\
\hline Condutividade & Determinada com um medidor marca Hanna modelo 3366. \\
\hline Sólidos Totais dissolvidos & Determinada com um medidor marca Hanna modelo 3366. \\
\hline Sólidos Totais em Suspensão & $\begin{array}{l}\text { Determinado pelo método Gravimétrico (Standard Methods } \\
\text { for the Examination of Water \& Wastewater 20Th - APHA- } \\
\text { AWWA-WEF - method } 2540-\text { D). }\end{array}$ \\
\hline Alcalinidade & $\begin{array}{l}\text { Estimada seguindo o método volumétrico, segundo } \\
\text { Standard Methods APHA-AWWA-WPCF (1980). }\end{array}$ \\
\hline Oxigênio Dissolvido & $\begin{array}{l}\text { Determinado pelo método de Winkler por Azida Modificada } \\
\text { (Standard Methods for the Examination of Water \& } \\
\text { Wastewater 20Th - APHA-AWWA-WEF - method } 4500 \text { O - } \\
\text { C). Tal método baseia-se na oxidação dos sais } \\
\text { manganosos em sais mangânicos pelo oxigênio que, } \\
\text { assim, são titulados de forma indireta por tiossulfato de } \\
\text { sódio. }\end{array}$ \\
\hline
\end{tabular}




\begin{tabular}{ll}
\hline Demanda Bioquímica de Oxigênio & Determinado por titulação (Standard Methods for the \\
& Examination of Water \& Wastewater 20Th - APHA-AWWA- \\
& WEF - method 5210 B e 4500 O C). \\
\hline Demanda Química de Oxigênio & Determinado por titulação (Standard Methods for the \\
& Examination of Water \& Wastewater 20Th - APHA-AWWA- \\
& WEF - method 5220 B,5220 D). \\
\hline Cloreto & Determinado pelo método de titulação com Nitrato de \\
& (Standard Methods for the Examination of Water \& \\
& Wastewater 20Th - APHA-AWWA-WEF - method 4500 - \\
& Cl-) \\
\hline Nitrato & Determinado por espectrofotômetro (Standard Methods for \\
& the Examination of Water \& Wastewater 20Th - APHA- \\
& AWWA-WEF - method 4500-NO3 - B). \\
\hline Óleos e Graxas & Determinado por gravimetria (Standard Methods for the \\
& Examination of Water \& Wastewater 20Th - APHA-AWWA- \\
& WEF - method 5220 D).
\end{tabular}

Paralelamente à coleta de amostras, foi realizada a medição de altura da lâmina d'água (profundidade) em intervalos de 30 minutos, iniciando às 6:30h horas e finalizando às $18: 30 \mathrm{~h}$, utilizando a ponte que passa por cima do ponto de referência onde foram coletadas as amostras.

Para determinar a altura da maré foi selecionado o ponto de referência da ponte de ferro, usando para isto uma corda graduada com peso no extremo inferior, para determinar a distância do ponto de referência até o leito do igarapé (hi) ${ }^{3}$, o qual é um valor fixo. Então, as medições seguintes foram realizadas da base da ponte até o nível d'água. Assim, medindo a distância entre o ponto de referência e a lâmina d'água, foi possível determinar a profundidade do Igarapé ao longo da enchente e da vazante (hx) com destaque para a PM (h2) e BM (h1), como ilustrado no Gráfico 1.

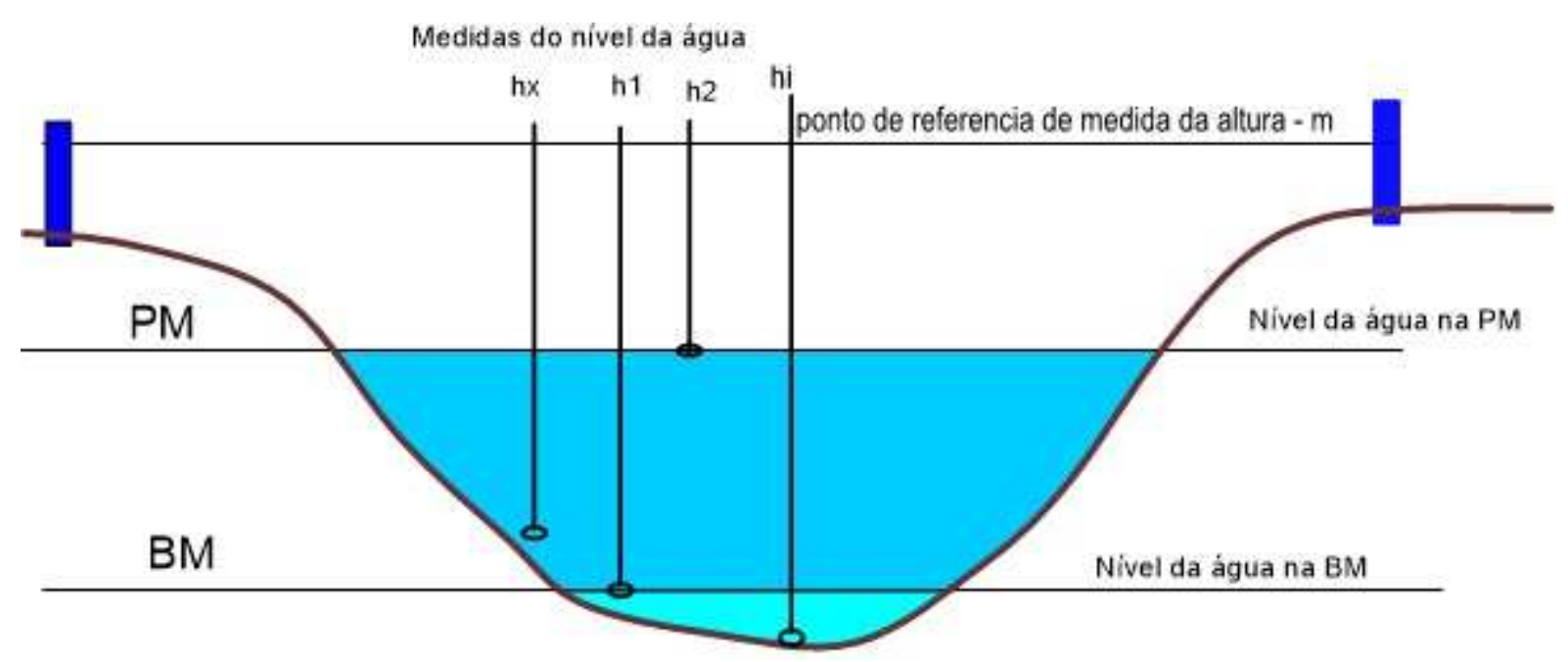

FIGURA 4 - Metodologia utilizada para determinação da altura da lâmina da Fonte: Modificado de MORALES (2002).

${ }^{3}$ Esse valor é constante já que mede a distância entre dois pontos fixos, o ponto de referência na ponte de ferro e o leito do Igarapé. O valor encontrado foi de $6.86 \mathrm{~m}$. 
A altura da maré foi realizada através da seguinte operação:

Altura da maré na BAIXAMAR:

$$
\mathrm{HM}_{\mathrm{BM}}=\mathrm{hi}-\mathrm{h} 1
$$

Altura da maré na PRE-AMAR:

$$
H M_{P M}=h i-h 2
$$

Altura da maré num momento $\mathrm{x}$ :

$$
H M_{x M}=h i-h x
$$

Onde:

$\mathrm{PM}=\mathrm{PRE}-\mathrm{AMAR}-\mathrm{m}$

$\mathrm{BM}=\mathrm{BAIXAMAR}-\mathrm{m}$

$\mathrm{hi}=$ Distância em $\mathrm{m}$ do ponto de referência para o leito do igarapé

$\mathrm{h} 1$ = distancia em $\mathrm{m}$ do ponto de referência à Lâmina de água na BM

$\mathrm{h} 2$ = distancia em $\mathrm{m}$ do ponto de referência à Lâmina de água na BM

$\mathrm{hx}=$ distancia em $\mathrm{m}$ do ponto de referência à Lâmina de água num momento $\mathrm{x}$

\section{RESULTADOS E DISCUSSÃO}

O Gráfico 1 mostra a curva do comportamento típico da maré, que se apresenta na forma de sino, característica de um comportamento polinomial com coeficiente de explicação de $87,58 \%$ dos dados. Além disso, esse comportamento é representativo de corpos hídricos da região amazônica com influência da maré (MORALES, 2002).

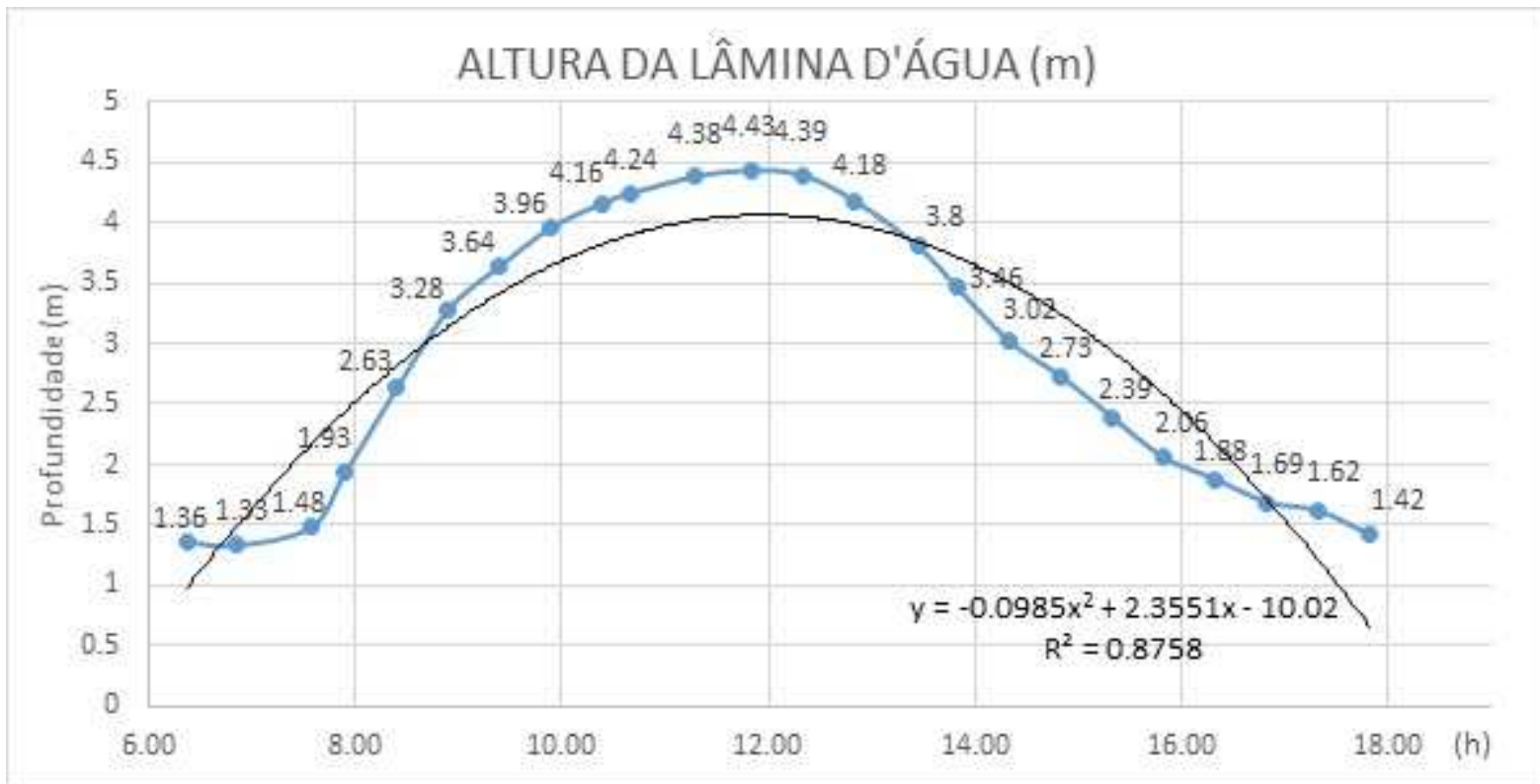

GRÁFICO 1 - Comportamento do nível d'água do Igarapé Tucunduba com a influência de marés. 
A Tabela 2 mostra o resultado e a hora da BM e PM, mudança da direção dos fluxos da água, comparando com os dados disponibilizados no site da Marinha do Brasil. O controle de maré foi realizado seguindo as informações disponibilizadas pela Marinha do Brasil (2014), no qual mostra que na data de 08 de Outubro de 2014, o final da vazante seria às 06:24h, o final da enchente às 11:06h e novamente o final da vazante às 18:39h, como mostra a Tabela 2.

TABELA 2 - Comparação do comportamento de maré fornecido pela Marinha do Brasil (2014) e o comportamento obtido em campo.

\begin{tabular}{llll}
\hline \multicolumn{2}{c}{$\begin{array}{c}\text { Comportamento Fornecido pela } \\
\text { Marinha do Brasil (2014) }\end{array}$} & \multicolumn{2}{c}{ Comportamento Obtido em Campo } \\
\hline $\begin{array}{l}\text { HORA } \\
\text { 6:24h }\end{array}$ & DIREÇÃO DO FLUXO DE ÁGUA & HORA & DIREÇÃO DO FLUXO DE ÁGUA \\
11:06h & Água saindo para o Rio (Vazante) & $11: 50 \mathrm{~h}$ & Água saindo para o Rio (Vazante) \\
18:39h & Água entrando no Igarapé (Cheia) & $18: 00 \mathrm{~h}$ & Água saindo para o Rio (Vazante) \\
\hline
\end{tabular}

Como é possível verificar na Tabela 2, existe uma ligeira diferença entre os dados disponibilizados pela Marinha do BRASIL (2014) e os registrados em campo. A BM ocorreu às 7:50h, diferente do disponibilizado pela Marinha do Brasil. As diferenças dos dados obtidos em campo com os disponibilizados pela Marinha do Brasil (2014) podem ter sido causadas pela distância do ponto de coleta de amostras e de controle de maré em relação ao Porto de Belém, onde são realizadas as medidas disponibilizadas pela Marinha do Brasil.

Os resultados do comportamento da maré mostram que na vazante, o igarapé apresenta dos dejetos gerados pela população alojada nas margens do igarapé e, na enchente, predomina a influência das águas do Rio Guamá. Âs 8:00h, se iniciou a enchente, atingindo o seu ponto máximo às $11: 50 \mathrm{~h}$, onde alcança a maior profundidade da lâmina da água $(4.43 \mathrm{~m})$ e, por conseguinte a maior altura da maré. A partir desse horário, inicia-se a vazante, até atingir a menor profundidade $(1.42 \mathrm{~m})$ e menor altura da maré às 17:50h. A Tabela 3 mostra os horários de coleta das amostras, com os respectivos corpos hídricos de maior influência.

TABELA 3 - Horários das amostras coletadas.

\begin{tabular}{ccc}
\hline HORA & COLETA & MAIOR INFLUÊNCIA \\
\hline $\mathbf{0 6 : 3 0}$ & Amostra 1 & Igarapé Tucunduba \\
\hline $\mathbf{0 8 : 0 0}$ & Amostra 2 & Rio Guamá \\
\hline $\mathbf{0 9 : 3 0}$ & Amostra 3 & Rio Guamá \\
\hline $\mathbf{1 1 : 0 0}$ & Amostra 4 & Rio Guamá \\
\hline $\mathbf{1 2 : 3 0}$ & Amostra 5 & Rio Guamá \\
\hline $\mathbf{1 4 : 0 0}$ & Amostra 6 & Ambos \\
\hline $\mathbf{1 5 : 3 0}$ & Amostra 7 & Igarapé Tucunduba \\
\hline $\mathbf{1 7 : 0 0}$ & Amostra 8 & Igarapé Tucunduba \\
\hline $\mathbf{1 8 : 3 0}$ & Amostra 9 & Igarapé Tucunduba \\
\hline
\end{tabular}

${ }^{4}$ No horário das 14:00h, como a vazante acabou de iniciar, ainda há muita água representativa do Rio Guamá, a qual entrou no Igarapé durante a enchente. Dessa forma, apesar da Amostra 6 ter sido coletada na vazante, ela ainda apresenta características mais marcantes da água do Rio Guamá, mas já com alguma influência da água do Igarapé Tucunduba. 


\section{Comportamento Dos Parâmetros Físico-Químicos}

Os resultados dos diferentes parâmetros analisados foram organizados, sistematizados e plotados em gráficos para facilitar a sua intepretação. No eixo $X$, foi plotada a hora (variável independente) e, no eixo $\mathrm{Y}$, os valores dos diferentes parâmetros analisados (variável dependente).

Os resultados da temperatura nas nove amostras apresentam pouca variação, como refletido no valor da sua média de $26,08^{\circ} \mathrm{C}$ e desvio padrão de 0,63 . As amostras coletadas na vazante mostraram valores mais elevados, atingindo valores de $29^{\circ} \mathrm{C}$, o que significa que as amostras de maior influência antrópica das margens do Igarapé Tucunduba mostraram os maiores valores de temperatura (Gráfico 2).

As alterações da temperatura estiveram associadas ao horário de coleta, com menores valores no início do dia e aumentando progressivamente no transcurso do horário. Valores anômalos das amostras coletadas no final da tarde mostraram menores valores da temperatura, provavelmente associados à precipitação que ocorreu no dia de coleta, de 17:53h até as 18:07h.

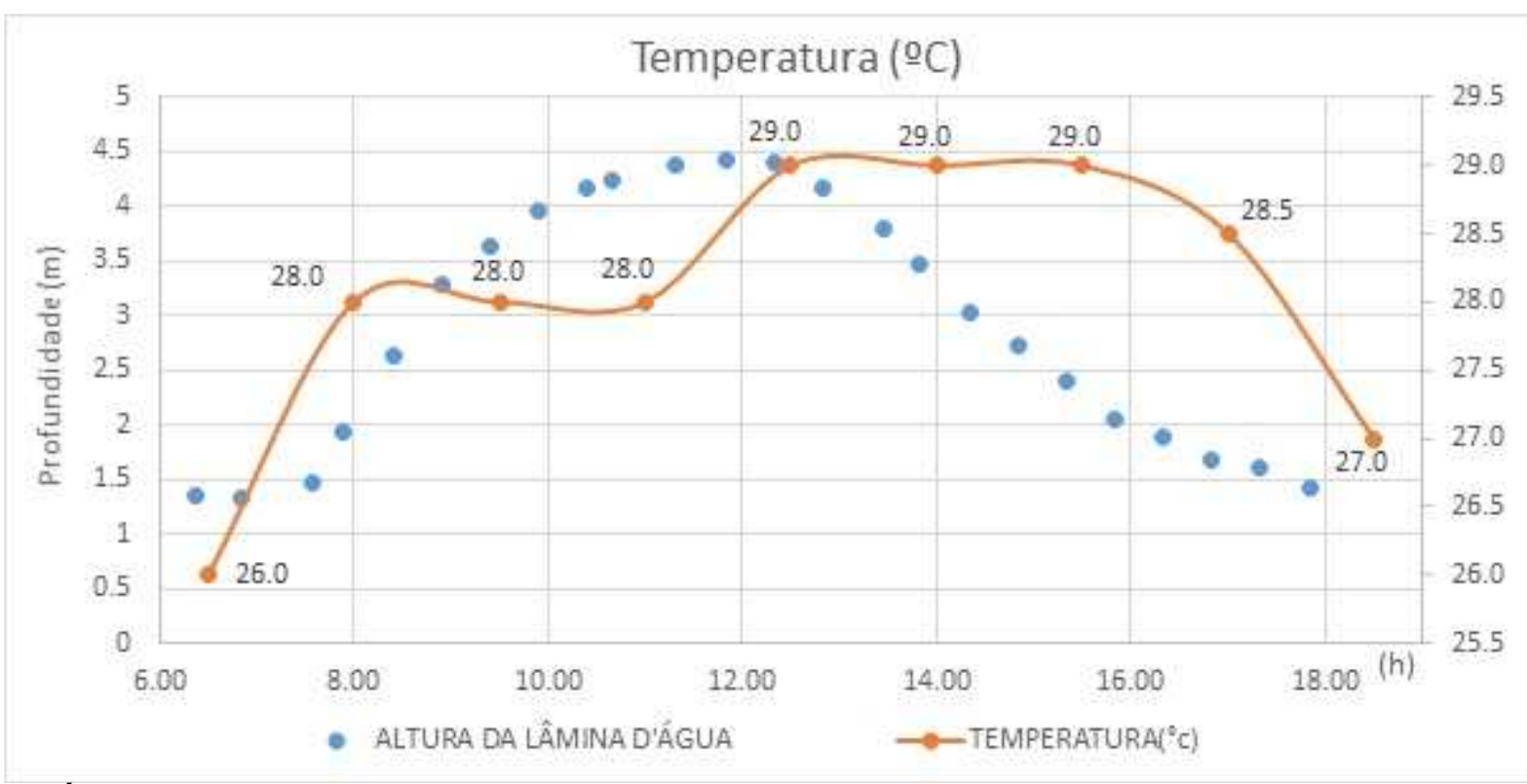

GRÁFICO 2 - Comportamento da Temperatura no Ponto de Controle da Maré.

O Potencial Hidrogeniônico $(\mathrm{pH})$ das amostras analisadas mostrou valores na faixa ácida, refletido na média de 6,10 , apresentando pouca variação nas nove amostras coletadas, pelo baixo valor de desvio padrão de 0,34 . A amostra coletada no horário $\mathrm{BM}$ das $6: 30 \mathrm{~h}$ apresentou o maior valor de $\mathrm{pH}$ (6.35), correspondente à maior influência da água do Igarapé Tucunduba. As amostras com maior influência do Rio Guamá mostraram valores mais ácidos, variando de 5.77 a 6.11 (Gráfico 3). Os valores de $\mathrm{pH}$ podem variar em função das características geoquímicas da área, da presença de efluentes líquidos com elevada carga orgânica e presença de ácidos orgânicos. 


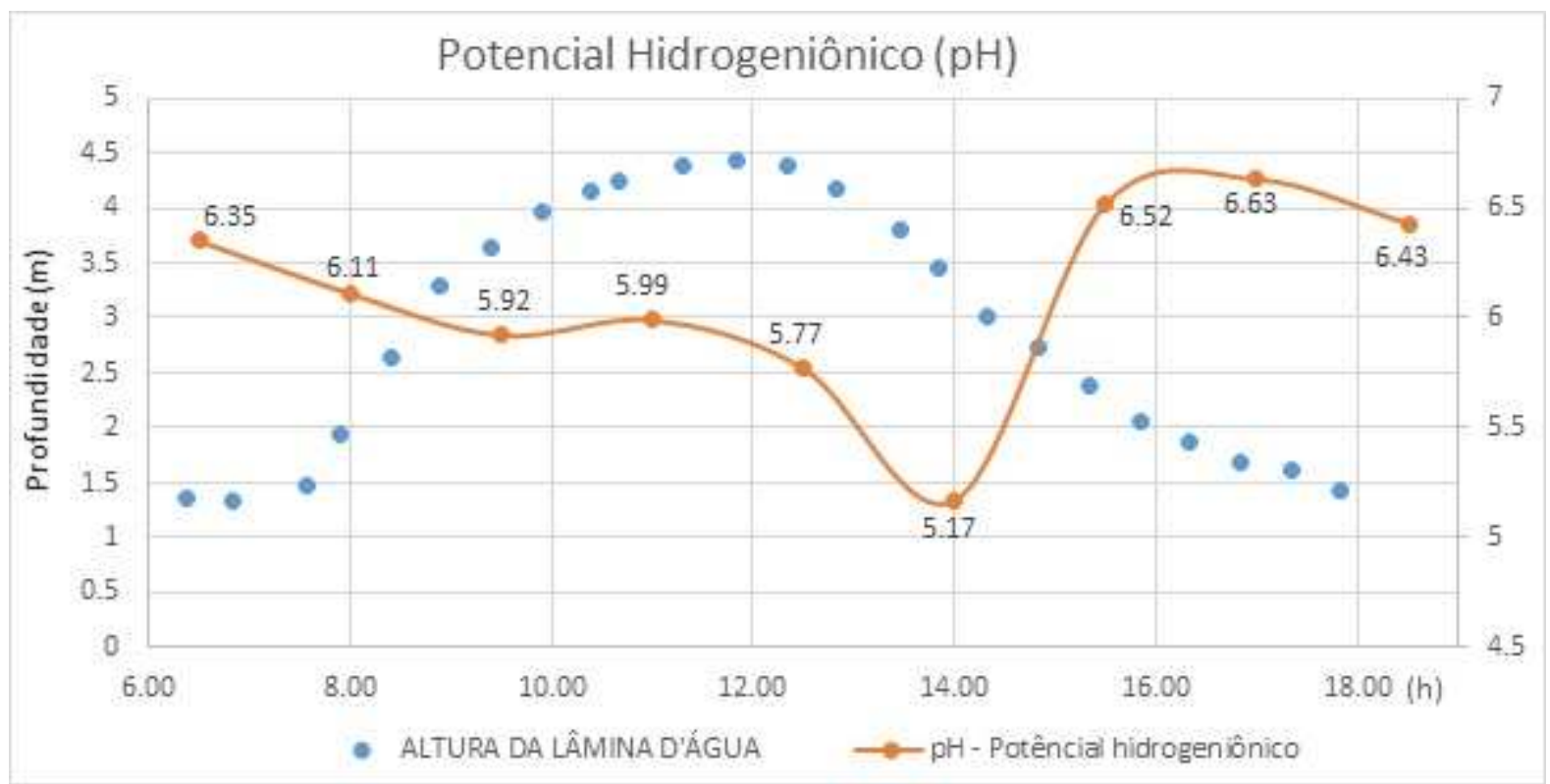

GRÁFICO 3 - Comportamento da pH no Ponto de Controle da Maré.

De acordo o Artigo 42 da resolução CONAMA 357/2005, o igarapé Tucunduba e o Rio Guamá podem ser enquadrados como água doce classe II, onde é definido o padrão de qualidade do pH na faixa de 6 a 9 (BRASIL, 2005). Assim, o Rio Guamá mostrou valores fora da faixa de aceitação. No entanto, valores de pH na faixa ácida podem ser considerados normais para águas da região amazônica, em virtude de que as águas do Igarapé Tucunduba podem ser classificadas como águas brancas amazônicas, caraterizadas por naturalmente apresentarem valores de $\mathrm{pH}$ na faixa ácida, segundo SIOLI (1984); ROSALES et al. (2002) e PASCOALOTO et al. (2012).

O Gráfico 4 mostra a variação do parâmetro cor nas nove amostras coletadas, evidenciando que as coletadas no horário com maior influência Rio Guamá apresentam os maiores valores, atingindo $100 \mathrm{uH}$. Os valores da cor mostraram variação significativa, como refletido no valor da média de 88,8 uH e desvio padrão de 12,34. As amostras de água coletadas na enchente - com maior influência do rio Guamá -, apresentaram o parâmetro da cor no limite do seu padrão de qualidade (75 uH), enquanto as amostras coletadas na vazante - com maior influência das atividades antrópicas desenvolvidas nas margens do Igarapé Tucunduba -, mostraram valores da cor acima do padrão de qualidade da resolução CONAMA 357/2005 (Gráfico 4). 


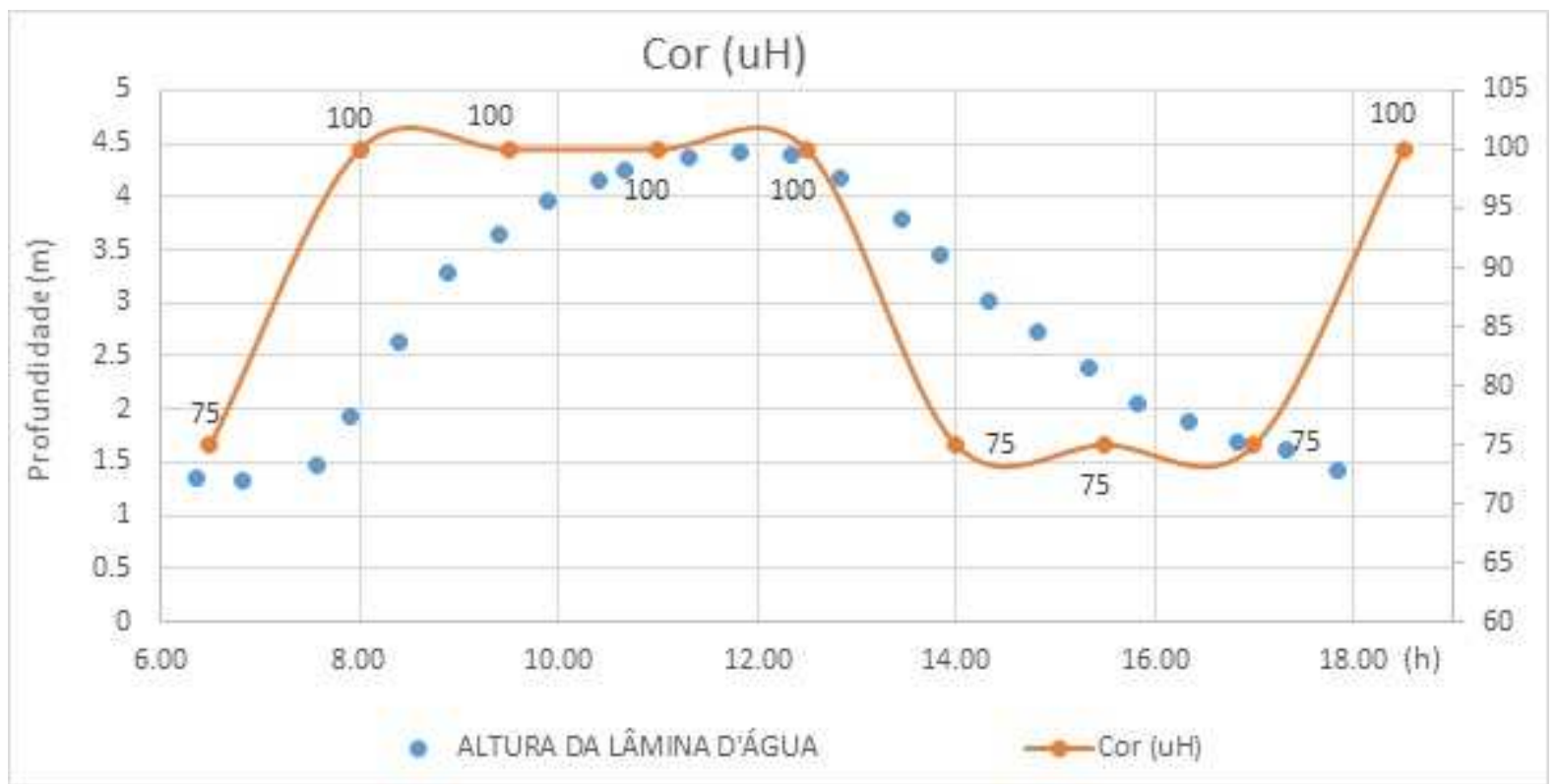

GRÁFICO 4 - Comportamento da Cor no Ponto de Controle da Maré.

Os resultados da Turbidez se mostraram aleatórios, como pode ser observado no gráfico 5 e no valor de seu coeficiente de correlação de $-0,05$. A turbidez é um parâmetro que está fortemente influenciado pela presença de material particulado, abundante na região estuarina, especialmente representado pela presencia de material argiloso suspenso. A resolução CONAMA 357/2005 define com em 100 UNT o padrão de qualidade, mostrando que $78 \%$ das amostras ficaram acima do valor máximo permitido, sendo as amostras coletadas horário de 15:30h e de 17:00h, as únicas que mostraram valores abaixo de 100 UNT.

Valores de turbidez acima do seu padrão de qualidade foram sempre encontrados nas águas do Rio Guamá e baia de Guajará, as quais são classificadas como águas brancas segundo SIOLI (1984). Na faixa ácida, ocorrem valores elevados de turbidez, pela presença de material em suspensão representado especialmente por argilas, além de elevados valores da cor verdadeira, de acordo com ROSALES et al. (2002) e PASCOALOTO et al. (2012).

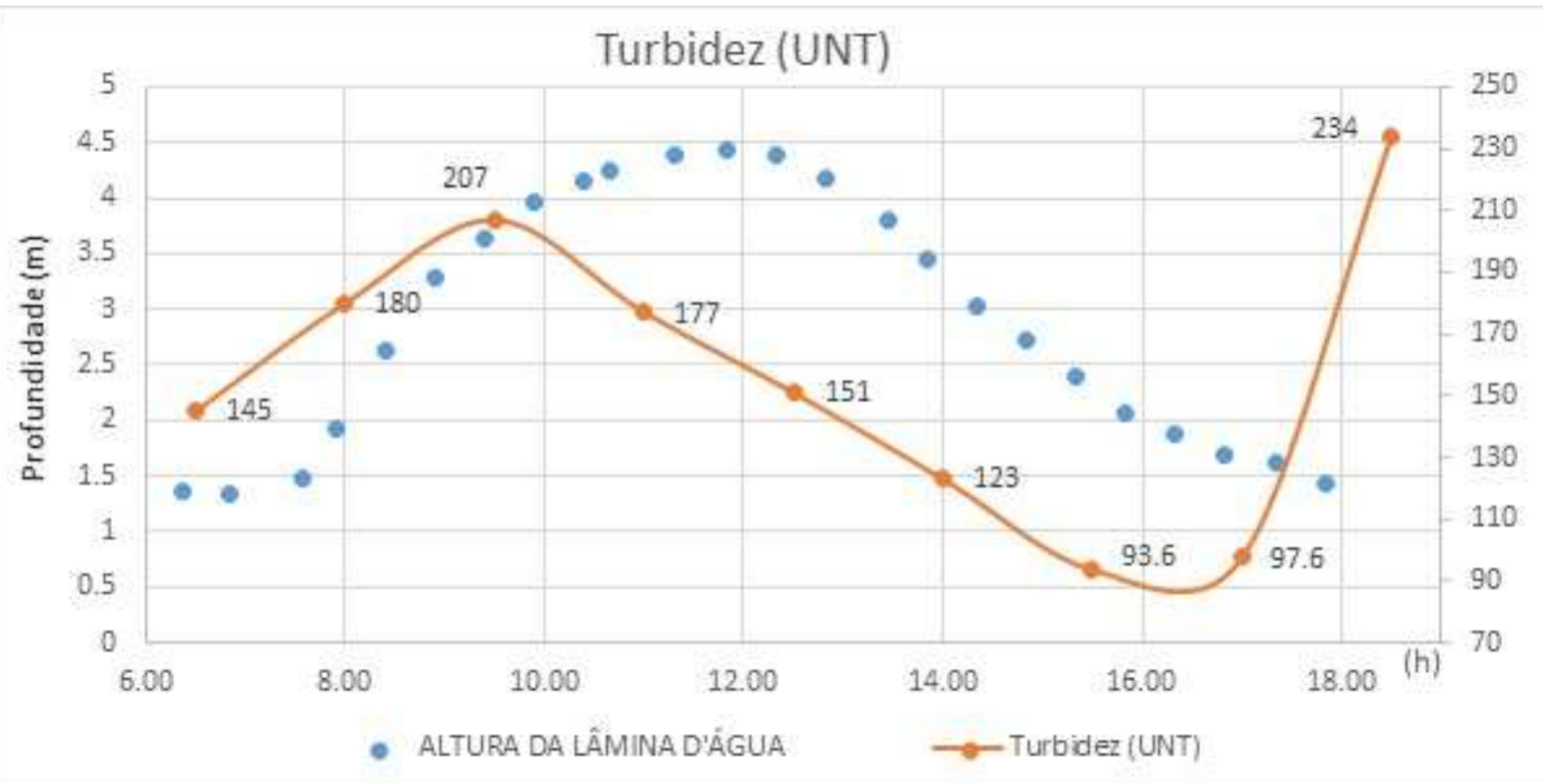

GRÁFICO 5 - Comportamento da Turbidez no Ponto de Controle da Maré.

ENCICLOPÉDIA BIOSFERA, Centro Científico Conhecer - Goiânia, v.11 n.22; p.129 
A condutividade e os Sólidos Totais Dissolvidos (STD) mostram comportamento similar, sendo inversamente proporcionais à altura da maré (gráficos 6 e 7). A condutividade e os sólidos totais dissolvidos são parâmetros bastante sensíveis, de grande utilidade na identificação de pequenas alterações nas características elétricas de corpos hídricos.

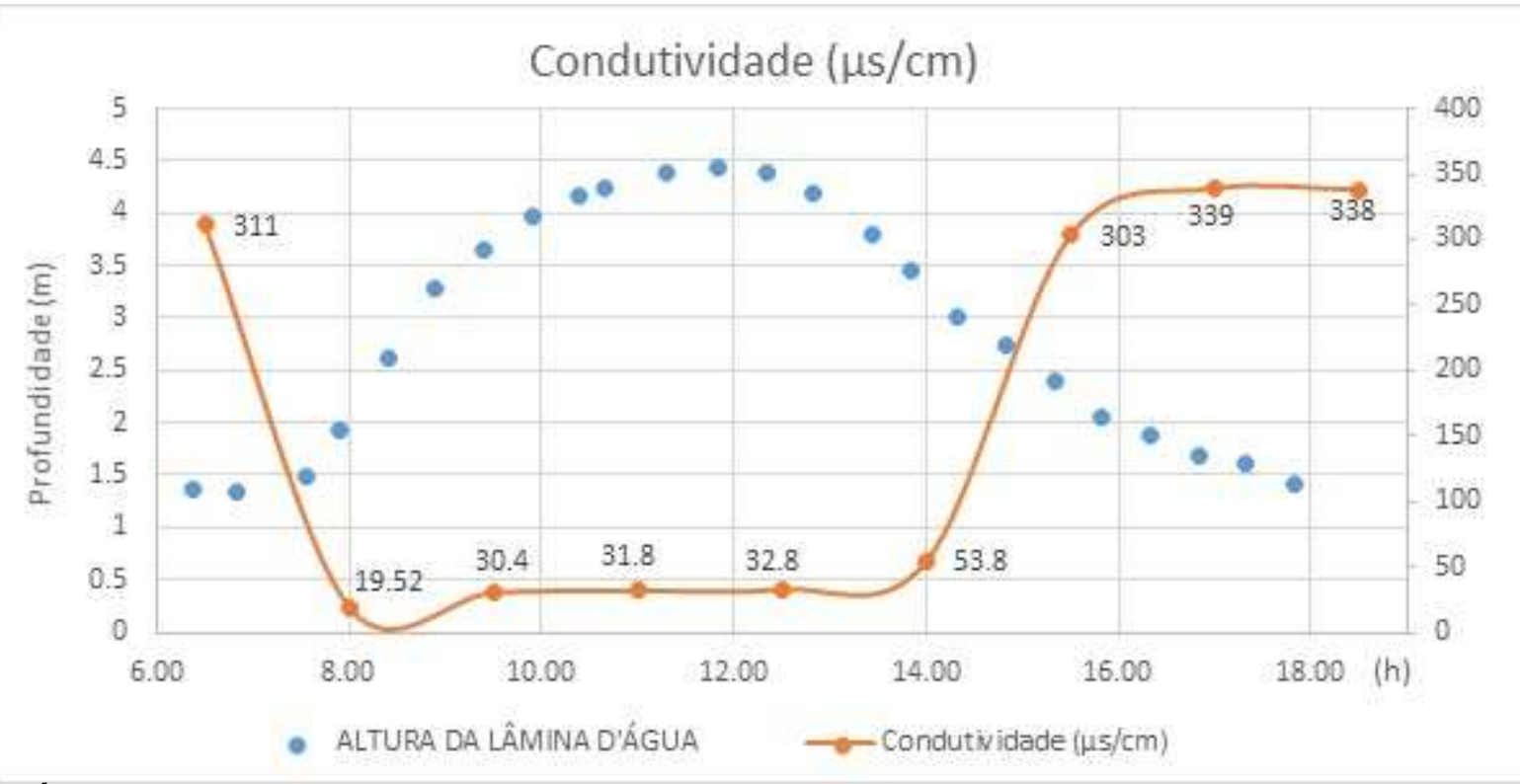

GRÁFICO 6 - Comportamento da Condutividade no Ponto de Controle da Maré.

De acordo com os valores expressos no gráfico 6 , é possível notar que a água com influência do Rio Guamá apresentou baixos valores, mudando entre 19,5 e $53,8 \mu \mathrm{S} / \mathrm{cm}$, valores bem menores os observados nas amostras coletadas na vazante - onde há maior influência das atividades antrópicas proveniente das margens do Igarapé Tucunduba -, que mostraram valores variando entre 303 e 338 $\mu \mathrm{S} / \mathrm{cm}$.

Verificou-se, então, que a água do Igarapé Tucunduba está significativamente impactada, como mostra a média de $332.75 \mu \mathrm{S} / \mathrm{cm}$, dez vezes maior do que a média dos valores encontrados nas amostras coletadas quando a maré recebe a maior influência do Rio Guamá, com valor de $28.63 \mu \mathrm{S} / \mathrm{cm}$. Valores elevados da condutividade elétrica podem estar associado com o lançamento de esgoto doméstico, efluentes industriais e resíduos sólidos.

Similar à condutividade, os sólidos totais dissolvidos mostraram comportamento inversamente proporcional à altura da maré. Os menores valores dos STD foram registrados na maré alta - com maior influência das águas do Rio Guamá - com teores variando de 9.76 a $16.4 \mathrm{mg} / \mathrm{L}$, enquanto as águas coletadas na maré baixa - com maior influência do Igarapé Tucunduba - exibiram teores de $152 \mathrm{a}$ $170 \mathrm{mg} / \mathrm{L}$ (Gráfico 7). 


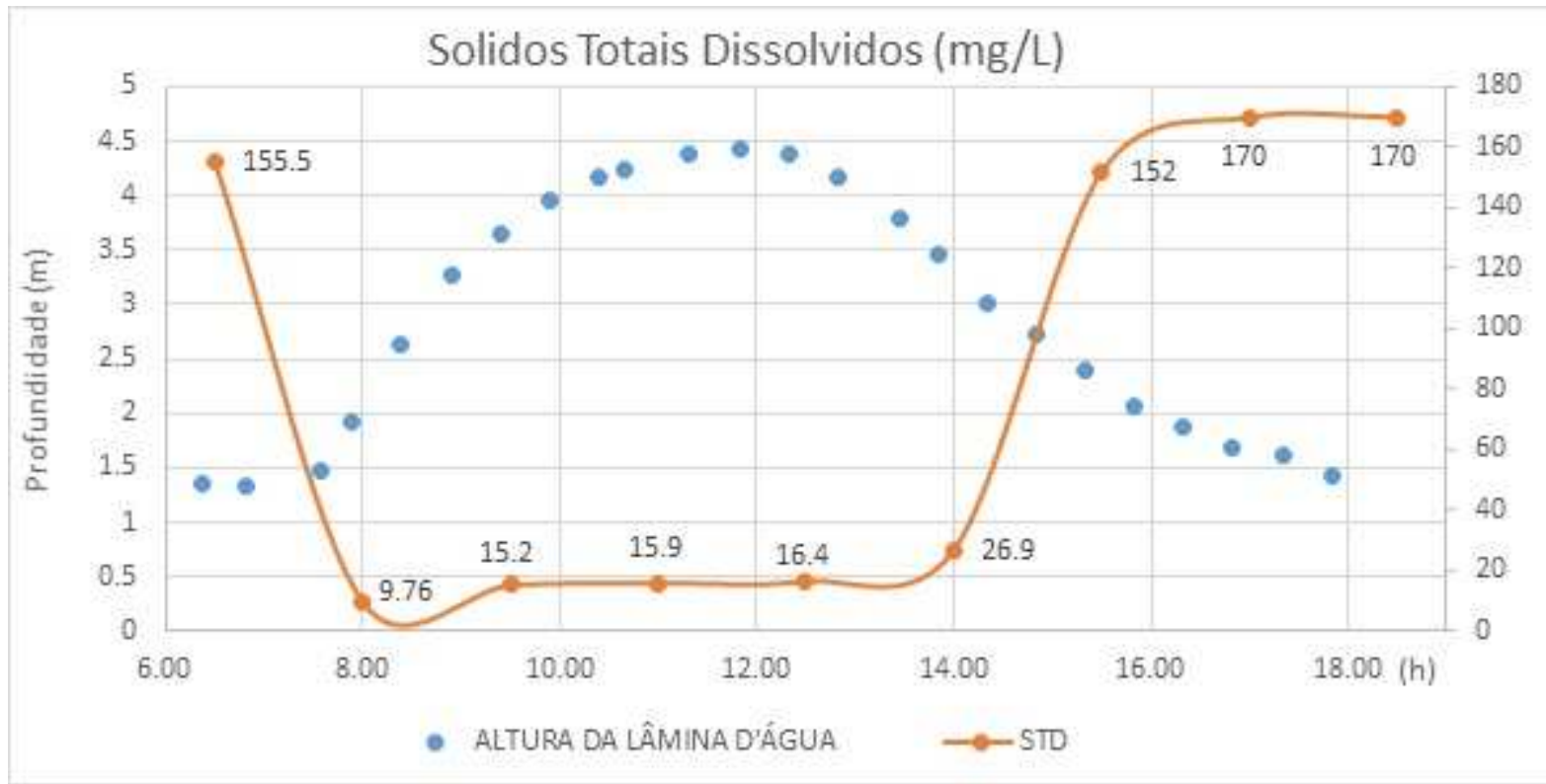

GRÁFICO 7 - Comportamento dos Sólidos Totais Dissolvidos no Ponto de Controle da Maré.

Em termos de STD, pode-se inferir que a água do Igarapé Tucunduba apresenta uma maior carga de poluentes iônicos em comparação à água do Rio Guamá. Os sólidos totais (ST) também chamados de resíduos totais estão relacionados diretamente com a condutividade elétrica e os STD (ESTEVES, 2011).

A resolução CONAMA 357 estabelece $500 \mathrm{mg} / \mathrm{L}$ como o padrão de qualidade para os STD, mas não tem padrão de qualidade para a condutividade, o que significa que ainda que alterada, a água do Igarapé Tucunduba encontra-se dentro do padrão de qualidade.

Os Sólidos Totais ST acompanharam o comportamento dos STD, com maiores valores nas amostras coletadas na vazante - com maior influência das águas do igarapé Tucunduba - e menores nas amostras coletadas na maré alta com predominância das águas do Rio Guamá (Gráfico 9).

O parâmetro da alcalinidade mostrou o mesmo padrão de comportamento dos STD e da condutividade, evidenciando que as águas do Igarapé Tucunduba apresentam uma alcalinidade maior em comparação às águas do rio Guamá. As amostras da água de maior influência do Igarapé Tucunduba apresentaram níveis de alcalinidade variando entre 80 e $90 \mathrm{mg} / \mathrm{L}$ de $\mathrm{CaCO}_{3}$, enquanto o valor encontrado na água com influência do Rio Guamá ficou próximo à $4 \mathrm{mg} / \mathrm{L}$ de $\mathrm{CaCO}_{3}$. 


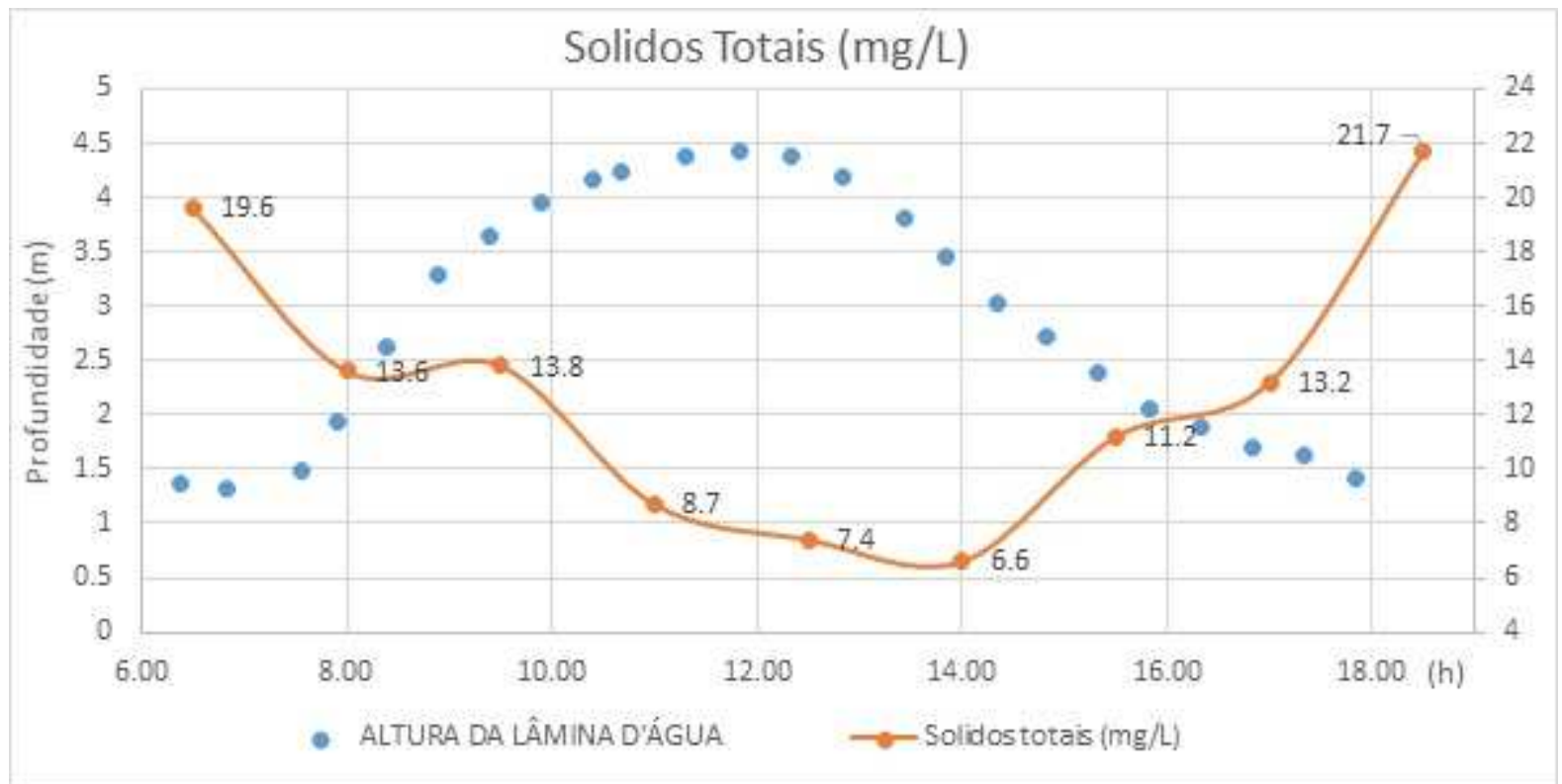

GRÁFICO 8 - Comportamento dos Sólidos Totais no Ponto de Controle da Maré.

Valores elevados da alcalinidade indicam presença de matéria orgânica em ambientes redutores, característicos de corpos hídricos impactados por esgotos domésticos, sendo esta a principal causa dos valores mais elevados nas águas do igarapé Tucunduba em relação às águas do Rio Guamá (CETESB, 2012).

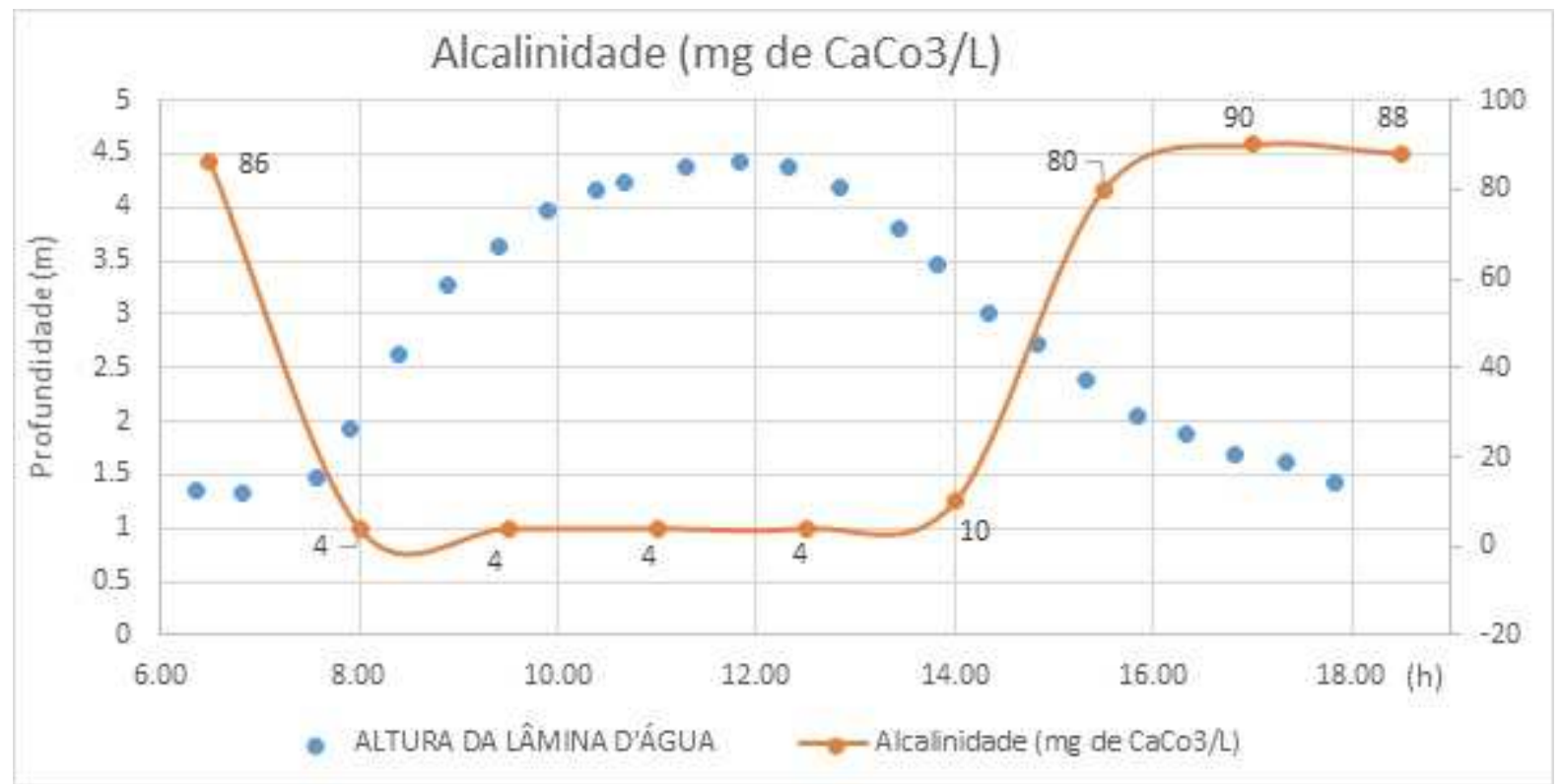

Gráfico 9 - Comportamento da Alcalinidade no Ponto de Controle da Maré.

O oxigênio dissolvido é um parâmetro importante na análise da qualidade ambiental do corpo hídrico e para a preservação das comunidades aquáticas (ESTEVES, 2011). 


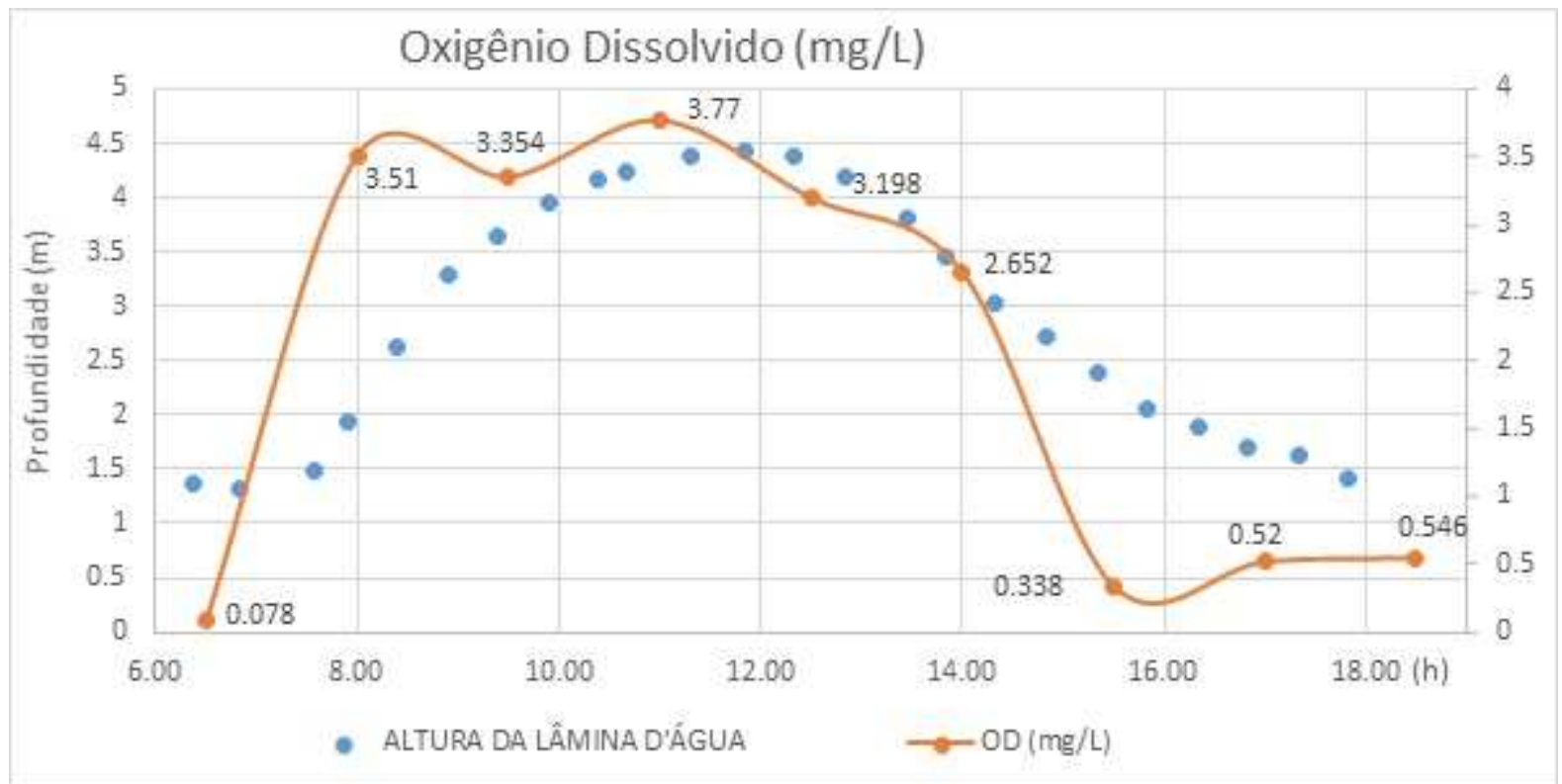

GRÁFICO 10 - Comportamento do Oxigênio Dissolvido no Ponto de Controle da Maré.

O valor mínimo estabelecido pelo CONAMA 357 para águas classe 2 é de 5 $\mathrm{mg} / \mathrm{L}$ de oxigênio dissolvido, mostrando que os teores encontrados nas amostras coletadas na vazante foram bem menores ao padrão de qualidade legislado. A maior concentração encontrada nas amostras de água com influência do Rio Guamá foi de $3.77 \mathrm{mg} / \mathrm{L}$.

No Igarapé Tucunduba, as concentrações foram ainda menores, variando de 0.078 a $0.546 \mathrm{mg} / \mathrm{L}$, consideradas como concentrações extremamente baixas de oxigênio dissolvido, causadas pela presença de matéria orgânica. Dessa forma, o grau de degradação ambiental do corpo hídrico é muito alto, uma vez que apresenta valores ínfimos de oxigênio, o que impede a vida aquática e estimula a atividade anaeróbia (VON SPERLING, 2014). Por fim, tanto a água com influência do Rio Guamá quanto a do Igarapé Tucunduba estão fora do padrão estabelecido pela resolução CONAMA 357/2005.

A Demanda Química de Oxigênio (DQO) e Demanda Bioquímica de Oxigênio (DBO) são dois parâmetros importantes para definir a qualidade da água superficial. Somente a DBO apresenta padrão de qualidade para águas doces classe II estabelecida pela resolução CONAMA 357/2005, que define o valor de $5 \mathrm{mg} / \mathrm{L}$ como seu valor máximo aceitável. Como pode ser observado no gráfico 11 , a água do Igarapé Tucunduba apresenta-se fora dos padrões.

Elevados valores na DBO indicam elevada quantidade de oxigênio necessária para oxidar a matéria orgânica por decomposição microbiana aeróbia. A presença de alto teor de matéria orgânica pode induzir à completa extinção do oxigênio na água (VON SPERLING, 2014). Na água com influência do Rio Guamá, a DBO encontrada variou de 1 a $1.5 \mathrm{mg} / \mathrm{L}$, dentro do padrão de qualidade, enquanto que as amostras de água coletadas na maré baixa, com maior influência da água do Igarapé Tucunduba, mostram valores variando entre 5.5 a $13 \mathrm{mg} / \mathrm{L}$. 


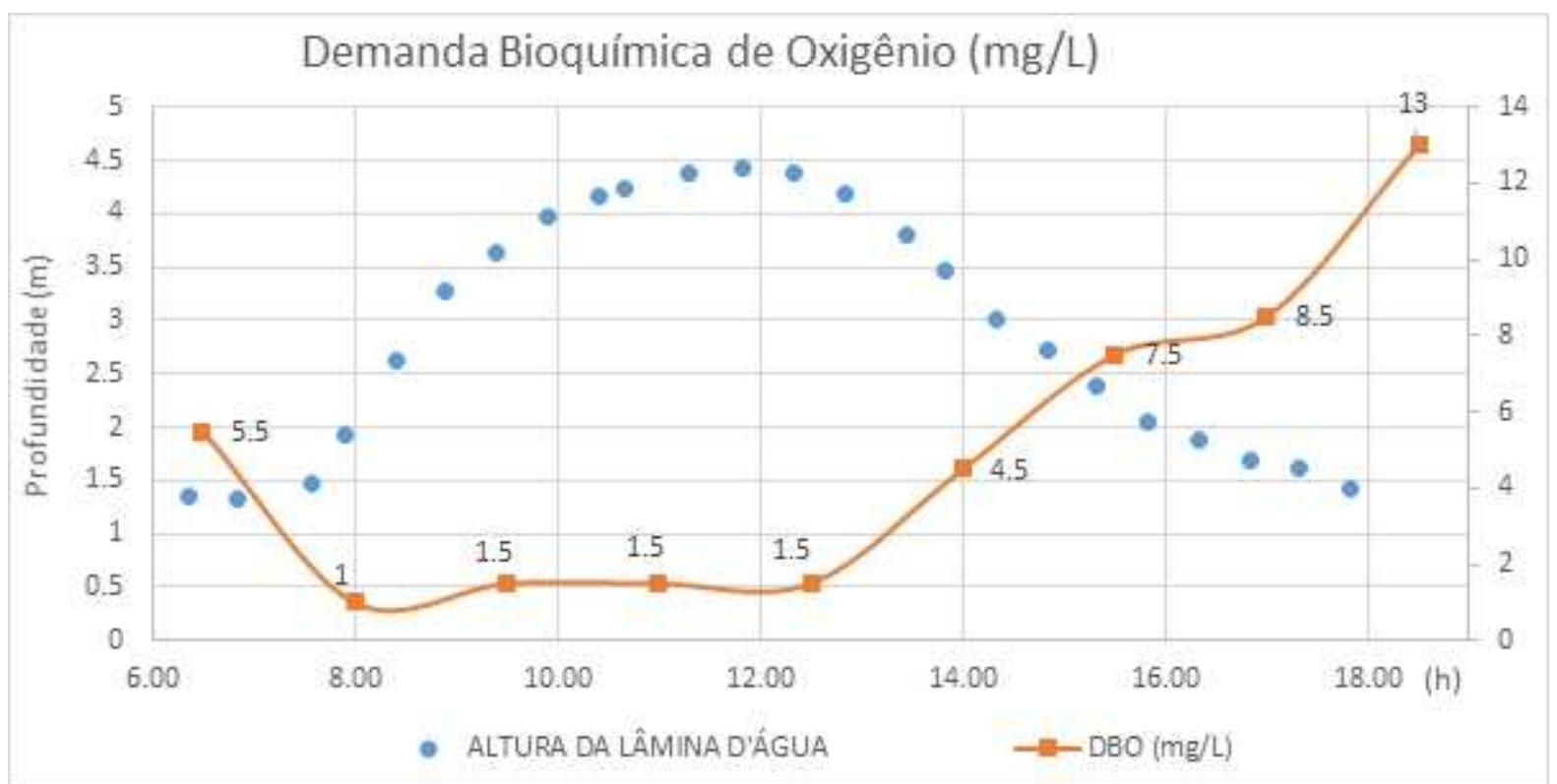

GRÁFICO 11 - Comportamento da Demanda Bioquímica de Oxigênio no Ponto de Controle da Maré.

Os elevados valores de DBO evidenciam grande quantidade de matéria orgânica presente, proveniente de esgoto doméstico ou matéria orgânica derivada de resíduos sólidos lançados no corpo hídrico. Deste modo, verifica-se que o esgoto doméstico despejado no lgarapé Tucunduba gerou grandes alterações no consumo de oxigênio.

A demanda química de oxigênio (DQO) representa a quantidade de oxigênio necessária para oxidação da matéria orgânica por meio de um agente químico. Os valores da DQO são maiores que os da DBO, pois a DBO representa somente a parcela biodegradável de matéria orgânica. Assim, ao comparar a DBO com a DQO, pode-se avaliar a biodegradabilidade do efluente: quanto mais o valor de DBO se aproximar da DQO, significa que mais biodegradável será o efluente (VON SPERLING, 2014). Na água com influência Igarapé Tucunduba, verificam-se valores variando de 20 a 30 , enquanto a DBO das amostras coletadas na maré alta com maior influência do Rio Guamá variou de 5.5 a 13 mg/L (gráfico 12).

A razão $\mathrm{DBO} / \mathrm{DQO}$ varia de 0.275 a 0.433 , o que significa que a parcela biodegradável representada pela matéria orgânica varia de $27.5 \%$ a $43 \%$ no corpo hídrico. Assim, os resultados de DQO confirmam a alta degradação do Igarapé Tucunduba no que diz respeito ao consumo de oxigênio por conta da presença de matéria orgânica, acrescentando a informação da biodegradabilidade dessa matéria orgânica encontrada. Quanto à resolução CONAMA 357/2005, esta não fixa valores máximos de DQO. 


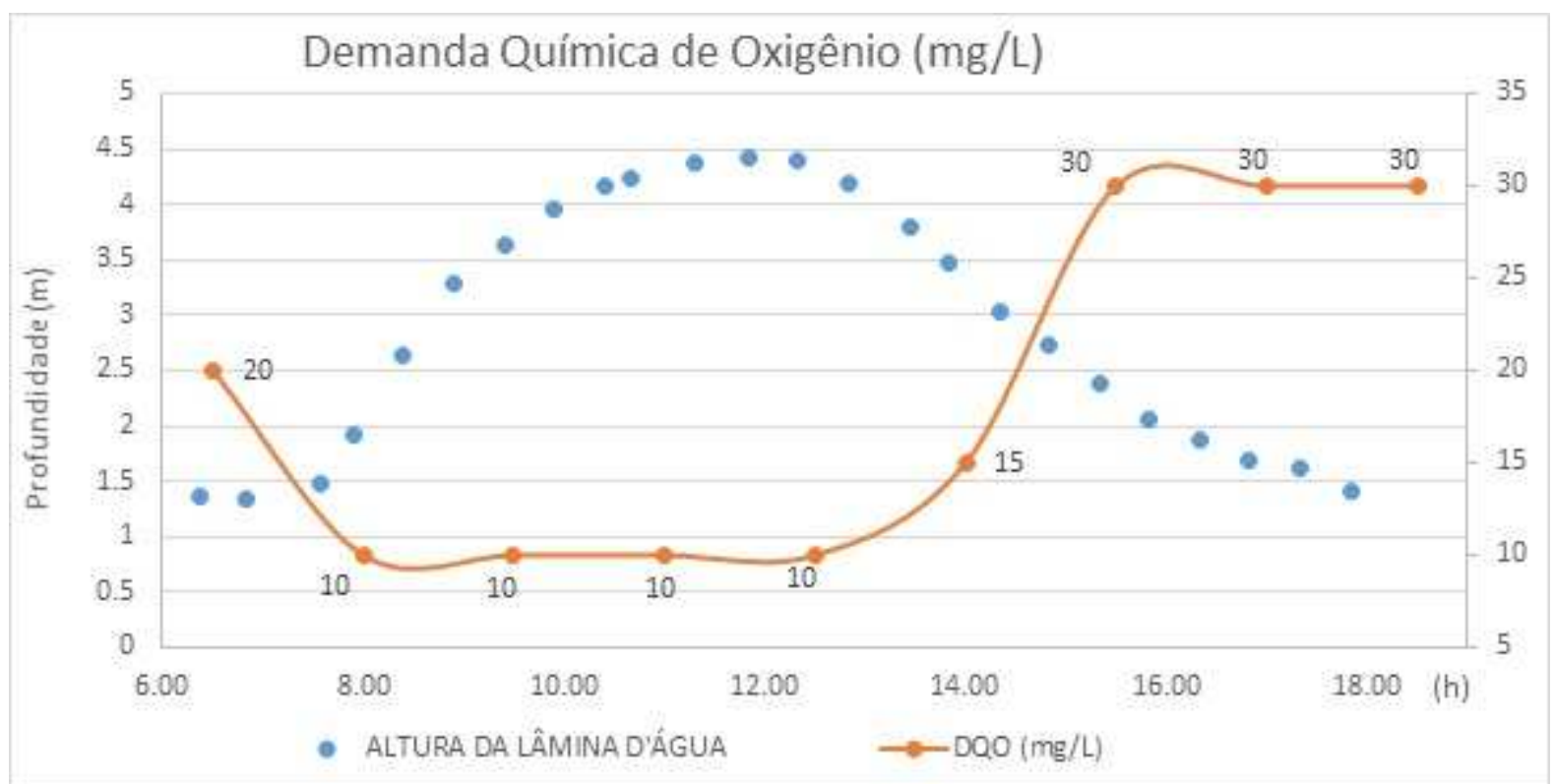

GRÁFICO 12 - Comportamento da Demanda Química de Oxigênio no Ponto de Controle da Maré.

O cloreto, junto com a DBO, STD e condutividade é um Parâmetro indicativo de qualidade ambiental de corpos hídricos. A quantidade de cloreto na água indica a presença de efluentes domésticos na água, por ser um ânion presente em alta quantidade na urina humana, uma vez que cada pessoa expele cerca de $6 \mathrm{~g}$ de cloreto por dia. Dessa forma, seu comportamento ocorreu dentro do esperado, mostrando os altos níveis de cloreto na água de maior influência do Igarapé Tucunduba. Já a água de maior influência do Rio Guamá apresentou valores ínfimos de cloreto (Gráfico 13).

As quantidades encontradas na água de maior influência do Igarapé são cerca de 82 vezes maiores do que as do Rio Guamá. No entanto, a água ainda se apresenta dentro do padrão da resolução CONAMA 357/2005, a qual estabelece um valor máximo de $250 \mathrm{mg} / \mathrm{L}$ de Cloreto.

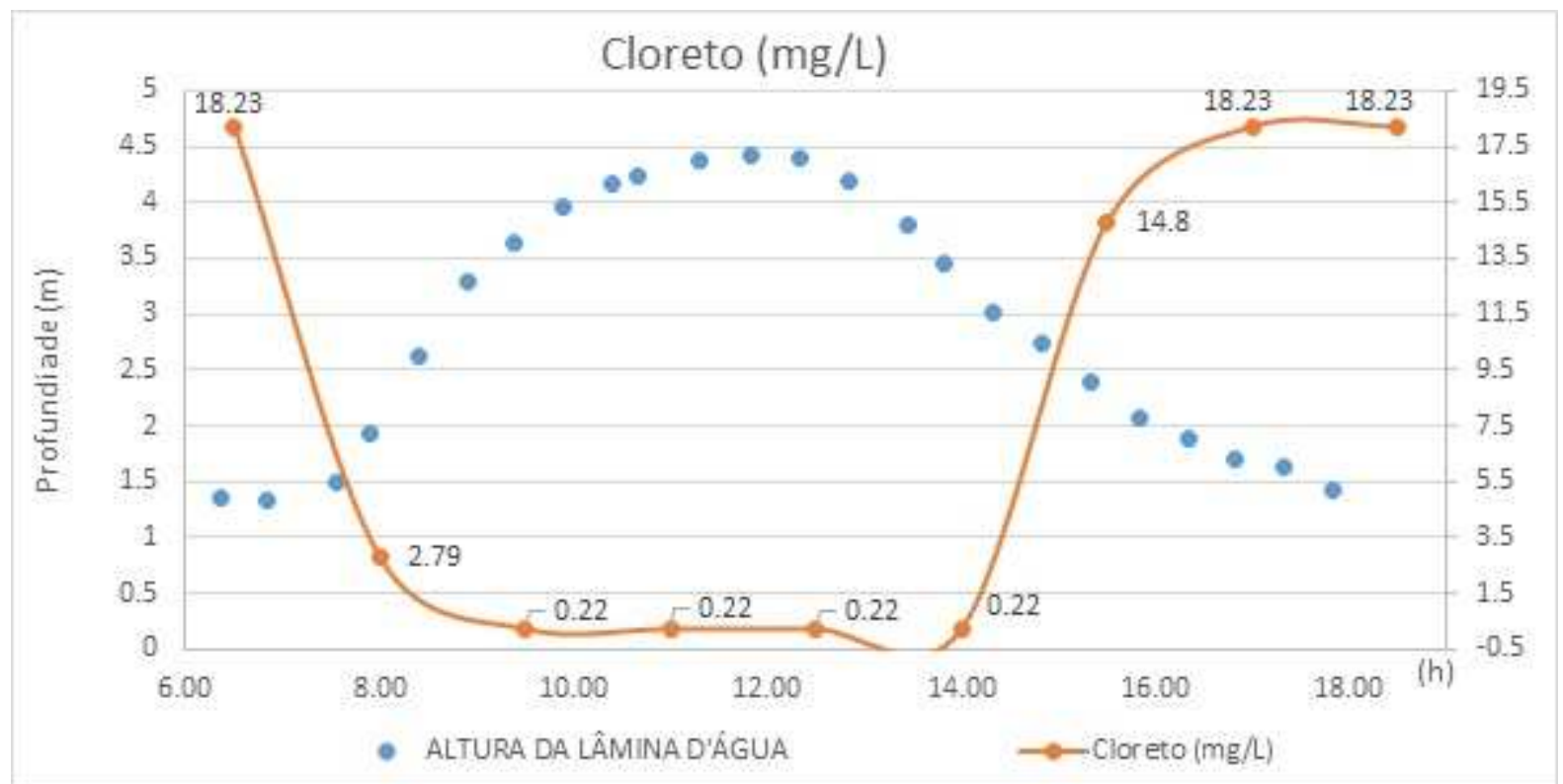

GRÁFICO 13 -Comportamento do Cloreto no Ponto de Controle da Maré. 


\section{CONCLUSÃo}

Após as análises dos parâmetros físico-químicos e suas respectivas relações com o comportamento da maré, pode-se concluir que, de fato, as amostras de água coletadas na foz do Igarapé Tucunduba sofrem duas influências importantes: durante a enchente refletem as características do Rio Guamá, com valores de $\mathrm{pH}$ na faixa ácida, valores baixos nos STD, condutividade, alcalinidade, DBO e cloreto, diferente das amostras coletadas na vazante, que mostram valores elevados da condutividade elétrica, STD, alcalinidade, condutividade e cloreto, com pH na faixa básica.

As amostras coletadas na vazante mostram forte influência das atividades antrópicas derivadas da ocupação desordenadas das margens do igarapé Tucunduba, o que explica valores da condutividade e de cloreto dez e oitenta vezes maiores, respectivamente, nas amostras coletadas na vazante em relação às amostras coletadas na enchente.

O comportamento diferenciado, nas amostras coletadas na vazante e na enchente, dos parâmetros $\mathrm{pH}, \mathrm{OD}, \mathrm{DBO}, \mathrm{STD}, \mathrm{ST}$, condutividade e alcalinidade indicam que a ocupação desordenada presente nas margens do lgarapé Tucunduba, através das Comunidades do Riacho Doce e Pantanal, afetam drasticamente a qualidade da sua água.

Os parâmetros cloreto, DBO, STD, ST, condutividade e alcalinidade mostraram comportamento inversamente proporcional com a altura da maré, indicando que provavelmente, o despejo inadequado de esgoto doméstico é a principal causa deste comportamento, que pode estar causando a degradação do igarapé Tucunduba, sendo necessário realizar trabalhos mais apurados considerando outras variáveis, entre elas a sazonalidade, para determinar mais precisamente o impacto da ocupação antrópica na qualidade dos recursos hídricos do Igarapé Tucunduba.

A metodologia de um único ponto de coleta de amostras durante uma vazante e enchente a intervalos de tempo definidos se mostrou válida e pertinente para a avaliação dos parâmetros físico-químicos da água em corpos hídricos que experimentam influência da maré e áreas ocupadas que recebem impactos diretos de atividade antrópica.

\section{REFERÊNCIAS}

APHA, AWWA, WEF. Standard Methods for the Examination of Water and Wastewater. 21th Edition. Wasghington D.C. American Public Health Association. 2005.

BARBOSA, M. J. S.; SÁ, M. E. R.; SOUZA, A. L. Estudo de caso: Urbanização do Igarapé Tucunduba, Gestão de Rios Urbanos - Belém/Pará. Belém: UFPA, 2003.

BRASIL. Conselho Nacional do Meio Ambiente (CONAMA). Resolução CONAMA № 357/2005, 18 de março de 2005. Publicação DOU no 053, de 18/03/2005.

BRASIL. NOVO CÓDIGO FLORESTAL. Lei № 12.651, de 25 de Maio de 2012. Disponível em: <www.planalto.gov.br/ccivil_03/_Ato20112014/2012/Lei/L12651.htm>. Acesso em 12 jul. 2015. 
CETESB, São Paulo. Qualidade das águas superficiais no estado de São Paulo 2011. São Paulo: CETESB, 2012.

CODEM, Companhia de Desenvolvimento e Administração da Área Metropolitana de Belém. Plano de Recuperação das Baixadas - Programa de Intervenção na Bacia do Una: Reestruturação Espacial. Belém. 1987.

COLARES, A. (2013). Tucunduba - do lugar da resistência ao lugar da perversidade: um estudo sobre a criminalidade do tráfico de drogas em uma favela na baixada de Belém. Disponível em: $<$ http://www.agb.org.br/evento/download.php?idTrabalho=142>. Acesso em: 12 jun 2015.

ESTEVES, F. Fundamentos de Limnologia, 3 ed. Rio de Janeiro: Interciência, 2011. p: 826.

FERREIRA, Carmena F. Produção do espaço urbano e degradação ambiental: um estudo sobre a várzea do igarapé do Tucunduba (Belém-Pará) (dissertação) Programa de Pós-Graduação em geografia física do Departamento de geografia FFLCH/USP. São Paulo:1995.

MARINHA DO BRASIL, 2014. Tábua das Marés de Outubro de 2014. Disponível em: http://www.mar.mil.br/dhn/chm/box-previsao-mare/tabuas/105200ut2014.htm. Acesso em: 03 set. 2014.

MATOS, F. C. Caracterização Qualitativa dos Impactos Ambientais causados pela Ocupação Urbana no Igarapé Tucunduba, Belém - PA. Universidade de Taubaté, São $\quad$ Paulo, 2010. Disponível em: http://www.bdtd.unitau.br/tedesimplificado/tde arquivos/1/TDE-2012-08-

28T195316Z-157/Publico/Fernando\%20Cardoso\%20de\%20Matos.pdf Acesso em: 15 out. 2014.

MATOS, F.O.; PINHEIRO, L.P.; MORALES, G.P.; VASCONCELOS, R.C.; MOURA, Q.L. Influencia da Maré na Dissolução de Poluentes Gerados no Depósito de Resíduos Sólidos da Região Metropolitana de Belém-Pa. Enciclopédia Biosfera, Centro Científico Conhecer - Goiânia, v.7, n.13; 2011.

MORALES, G. P. 2002. Avaliação ambiental dos recursos hídricos, solos e sedimentos na área de abrangência do Depósito de Resíduos Sólidos do Aurá. Belém. Universidade Federal do Pará. Centro de Geociências. 220p. (Tese de Doutorado).

MORÁN, E. F. A ecologia das populações da Amazônia. Petrópolis: Vozes, 1990. $367 \mathrm{p}$.

NETO, R. D., CARDOSO, A. D. Ocupação de Margem de Rio na Metrópole Amazônica: origem local e tendências globais. 2012. Disponível em http://www.anpur.org.br/revista/rbeur/index.php/APP/article/view/3858/3772. Acesso em: 16 jun. 2015. 
PASCOALOTO, D; DA SILVA, M; BRINGE, S. 2012. Qualidade da água dos recursos hídricos na sede do município de São Gabriel da Cachoeira, AM IN: Projeto FRONTEIRA - Desvendando as fronteiras do conhecimento na região amazônica do alto rio negro. 350 p. 2012.

PIMENTEL et. al. A Ocupação das Várzeas na Cidade de Belém: causas e consequências socioambientais. Revista Geonorte, Edição Especial, V.2, N.4, p.34 - $45.2012 . \quad$ Disponível em: http://www.revistageonorte.ufam.edu.br/attachments/009 A\%20OCUPA\%C3\%87\%C 3\%830\%20DAS\%20V\%C3\%81RZEAS\%20NA\%20CIDADE\%20DE\%20BEL\%C3\%8 9M\%20CAUSAS\%20E\%20CONSEQ\%C3\%9C\%C3\%8ANCIAS\%20SOCIOAMBIEN TAIS..pdf Acesso em: 15 ago. 2015.

QUEIROZ, J. A. L. et al. Estrutura e Dinâmica de Floresta de Várzea no Estuário Amazônico no Estado do Amapá. FLORESTA, Curitiba, v. 37, n. 3. 2007. Disponível em: http://ojs.c3sl.ufpr.br/ojs/index.php/floresta/article/download/9930/6825. Acesso em: 12 ago. 2015.

RODRIGUES, R. M., et al. APP's urbanas e intervenções públicas em áreas de Baixadas em Belém (PA): implicações das intervenções públicas nas margens de cursos d'água. IN: Anais do Seminário Nacional sobre Áreas de Preservação Permanente em Meio Urbano. ANPUR, 2012. Disponível em: http://www.anpur.org.br/revista/rbeur/index.php/APP/article/view/4030. Acesso em: 15 ago. 2015.

ROSALES, J.; VARGAS, O.; RODRIGUES, M. (2002). "Hydrography and ecohydrology of the Guiana Shiel Ecoregion" in Anais do Guayana Shiel Conservation Priority Setting Workshop, Paramaribo, Abr 2002. Disponível em http://www.guianashield.org, acesso em 10 jul 2015.

SANTOS, V. J. C. Modelo de processo participativo de enquadramento aplicado a bacias hidrográficas urbanas: bacia do Tucunduba - PA. Dissertação (Mestrado) - Universidade Federal do Pará, Instituto de Tecnologia, Programa de Pós-Graduação em Engenharia Civil. Belém, 2010.

SIOLI, H. Hydrochemistry and geology in the Brazilian Amazon region. Amazoniana. v.1, p.74-83, 1984.

SUDAM. 1979. A ação da Sudam no Saneamento da Amazônia. In: CONGRESSO BRASILEIRO DE ENGENHARIA SANITÁRIA, 10, Rio de Janeiro. n.p.

VON SPERLING, M. Introdução à Qualidade Das Águas e ao Tratamento De Esgotos. 4a ed. Belo Horizonte: Departamento de Engenharia Sanitária e Ambiental; Universidade Federal de Minas Gerais, 2014. 